Journal of Engineering Sciences, Assiut University, Vol. 35, No. 4, pp. 1023-1039, July 2007

\title{
THE SUSTAINABLE DEVELOPMENT IN THE ARAB WORLD ON LOCAL REGIONAL LEVELS - A COMPARATIVE ANALYSIS OF THE REALITY AND THE SCOPE OF ARAB TOWNS
}

\author{
Saif Abdullah Ahmed AL-kubati \\ Prof. of Urban Design Arch. Department Faculty of Engineering, Sana'a \\ University Yemen Republic P.O.Box 14288 Sana'a \\ Alkobatisaif@yahoo.com
}

(Received April 14, 2007 Accepted June 4, 2007)

Towns play a major role in the development field; because they are productive places in general as they suitably contribute in the national economical growth. Yet the process of the urban development in itself generally causes a distinct deterioration of the surrounding environmental conditions. As towns are considered places for the population growth as well as for trading and industrial activities, they intensity the consumption of energy, the deterioration of resources and the production of wasteproducts to an extent, which surpasses the endurance of the systems created by the human being and nature together, as well as it confuses the administrative abilities of administrating these systems. The acute state of this situation deteriorates with the rapid growth of the population in towns. These harmful effects or the environmental loses resulting; threaten the continuity of the production of these towns, the health of their population and their kind living. The Arab towns are facing real challenges implemented by increasing urban growth and its effects on changing the social dynamics, that change will create new possibilities for social progress, but it will also increase the greater difficulties all towns face in supplying sufficient infrastructures. The skeleton structure for any town is affected by several factors, political, social, economical, modern technology and the climatic factor, which is very difficult to study its effects by itself, as it is one of the comparatively stable factors all through the passing years and eras compared with the other changing factors, therefore to organizing the skeleton of any town we have to bear in mind modern issues, like the population density, The crowdedness problem, the air movement, transport, other necessities of health, as well the climatic factors.

Several of the Arab towns administrations tried to face the new situations through development and modernization, yet the rate of increased construction growth surpassed all the expectations of these plans, which hindered the possibility of planning the suitable future directions of developing the public utilities, civil services, directing the population's activities, the investment movement, which would suit the situations the conditions and the growth constituents in these towns to realize the maximum benefit of its potentials and growth abilities. To overcome such defect most the Arab towns used to adopt plans more flexible, but they 
generally do not have a comprehensive look or integrating one between these towns and their surroundings, which generally consists of secondary towns or regions connected to these towns, which weakens the role of these towns in achieving the balance and looked for integrating growth on local and regional levels. For a sustainable development it must be balanced in a better way between the rural and urban areas, between little towns, middle and big ones adopting a method of development, whose axis is the human being, The ability of the towns to survive depends on their answering the people's needs through more effective investments in the fields of health, education ...etc. This needs the active share of the societies in the urban development, stressing role of women as full partners in the sustainable development.

KEYWORDS: Sustainable development, Environmental considerations
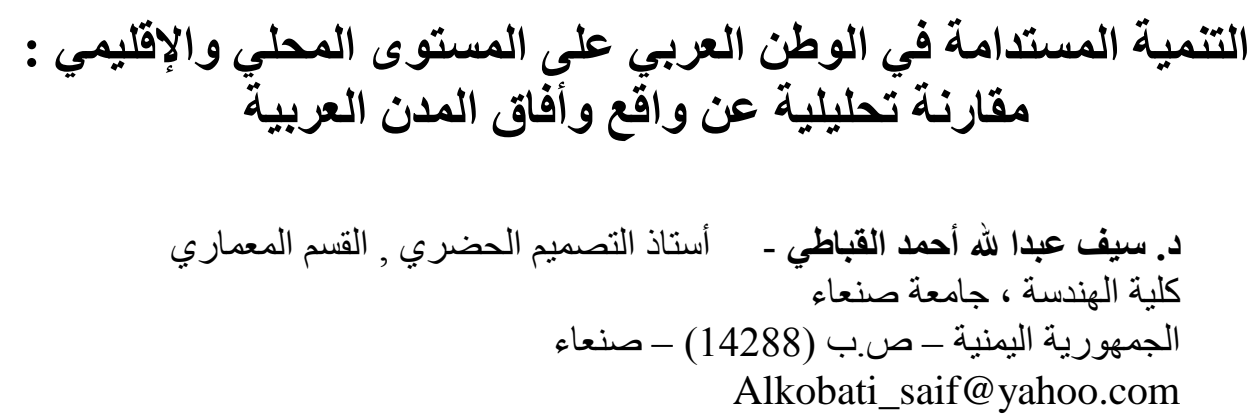

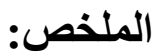

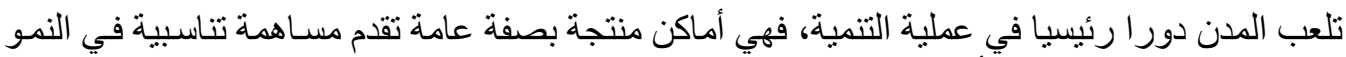

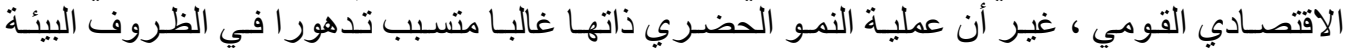

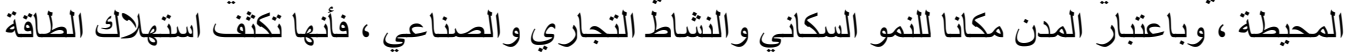

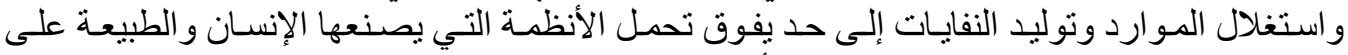

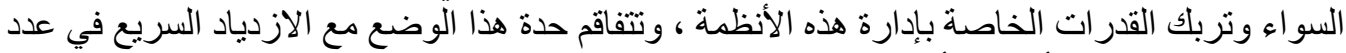

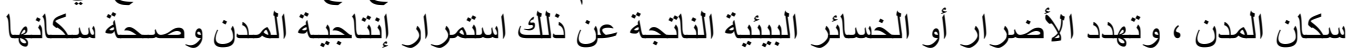

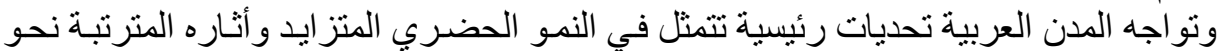

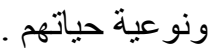

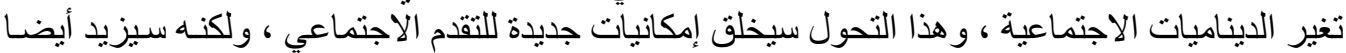

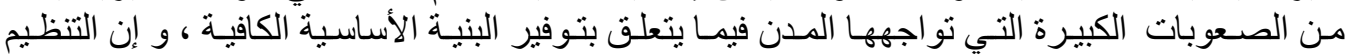

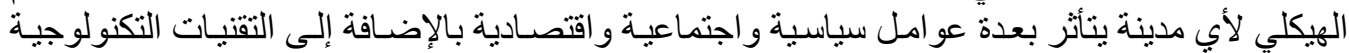

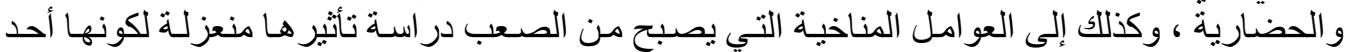

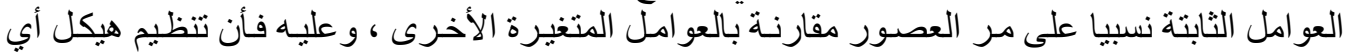

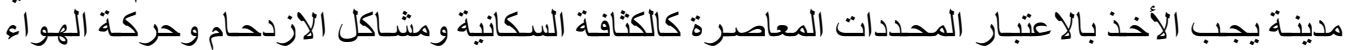

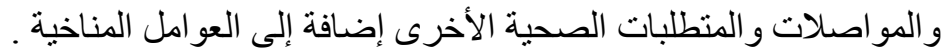




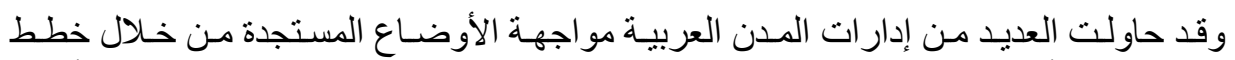

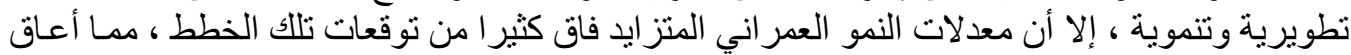

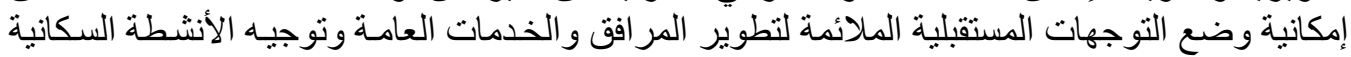

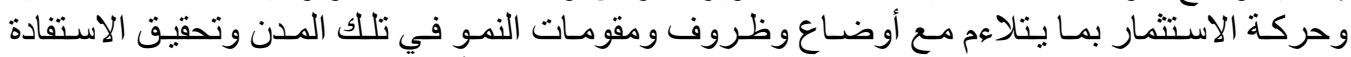

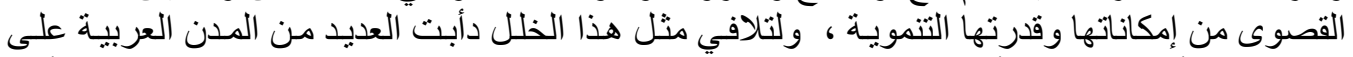

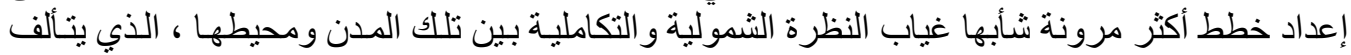

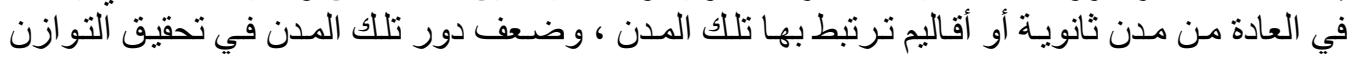

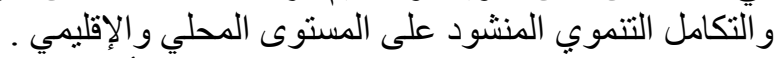

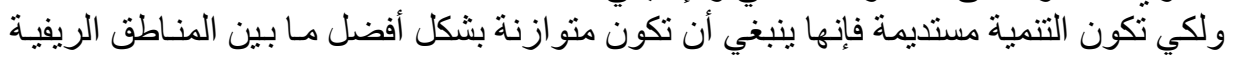

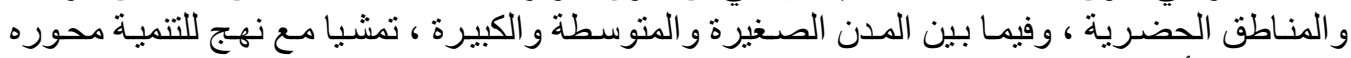

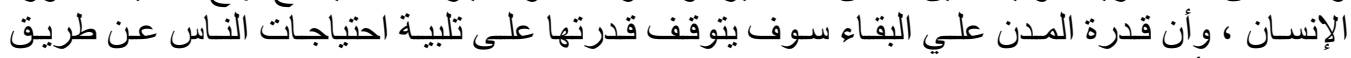

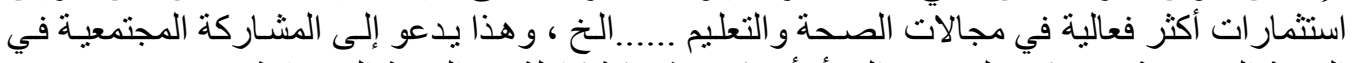
التنمية الحضرية ، ويؤكد على دور المر أة أن تكون شريكة كاملة في التنمية المستدامة .

\section{كلمات مفتاحيه : التنمية المستدامة , الاعتبار ات البيئية .}

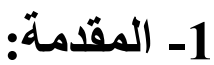

منذ قديم الزمان و الإنسان في محاو لات مستمرة للتفاعل الأمثل مع البيئة المحيطـة بـه بقصد توفير الحيز

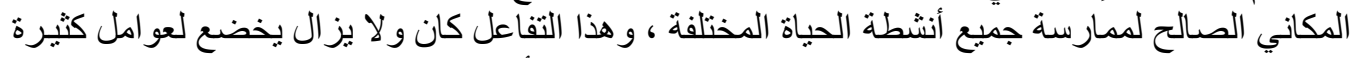

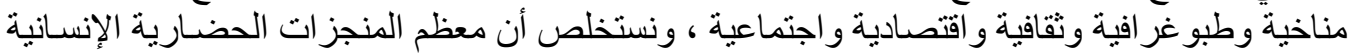

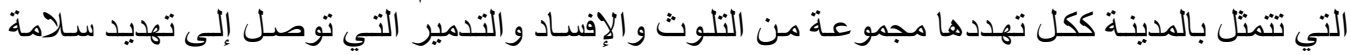

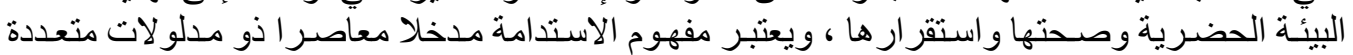

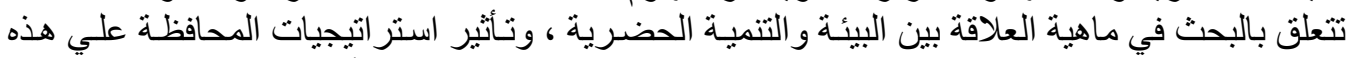

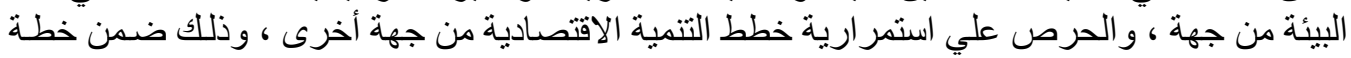

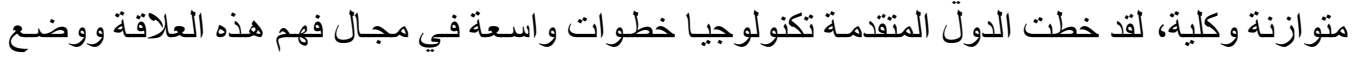

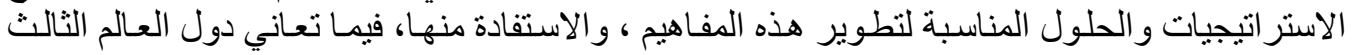

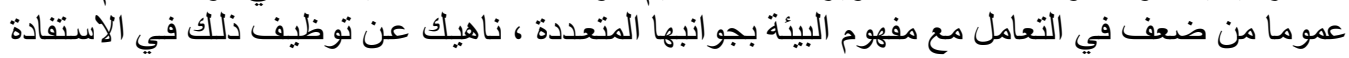

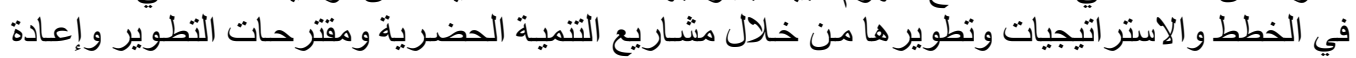

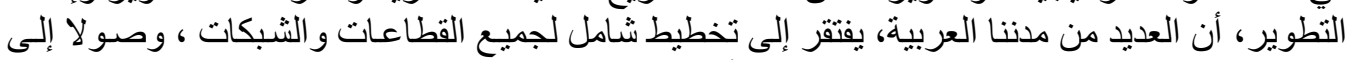

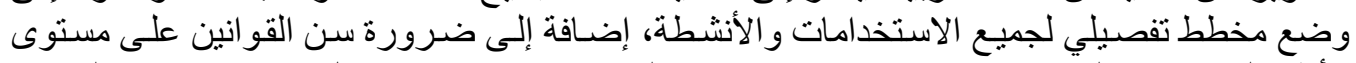

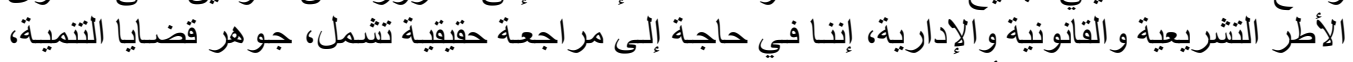

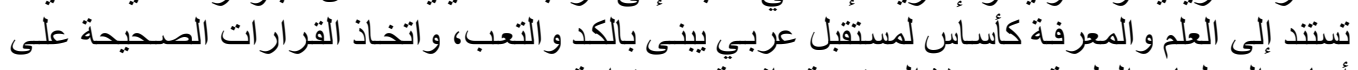

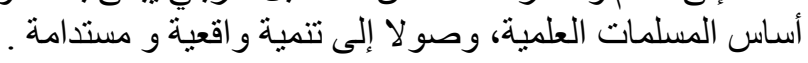

: 1-1

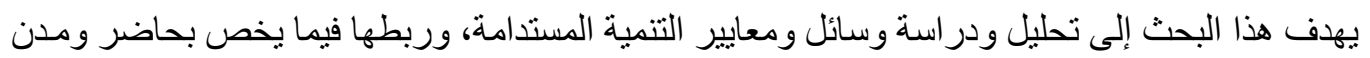

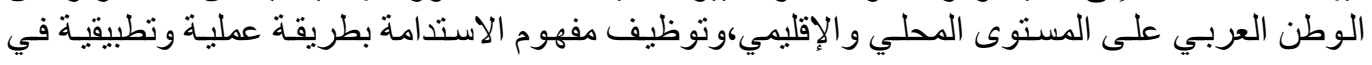
مشاريع التنمية .

\section{2-1}

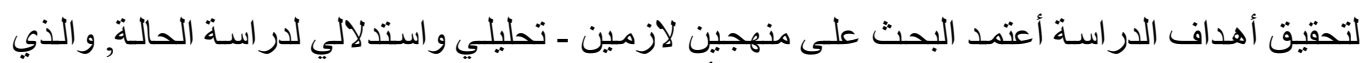

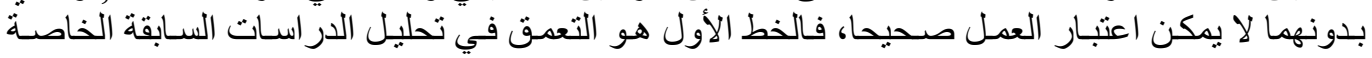


بمفـاهيم و اتجاهـات التنميـة الثـاملة والتصـورات الكاملـة في التشـكيلات الحضـرية على المستوى المحلي

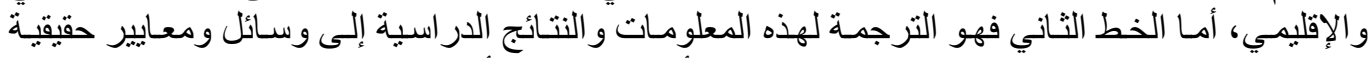

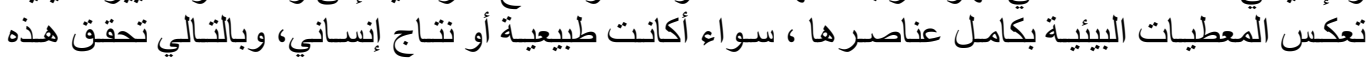

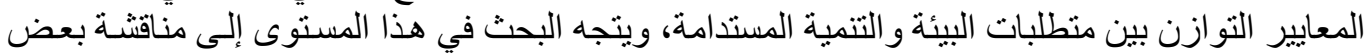

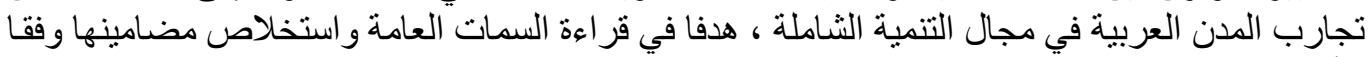

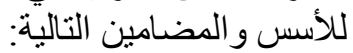
فهم العلاقة المتبادلة بين الإنسان وبيئته الحضرية

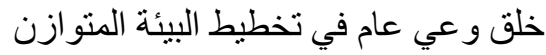

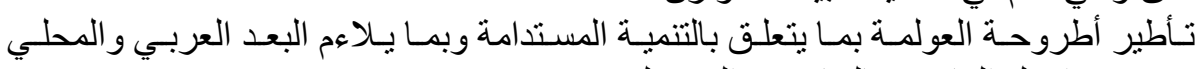

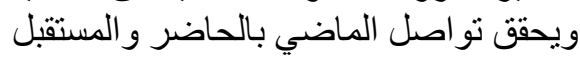
الوصـول لاستر اتيجيات متعددة الجو انب والا هتمامـات و المقاييس لشكل العلاقـة بين التنميـة وخصوصية المحيط.

\section{2- جلالية العلاقة بين الإنسان وبيئته الحضرية:}

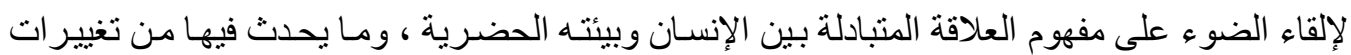

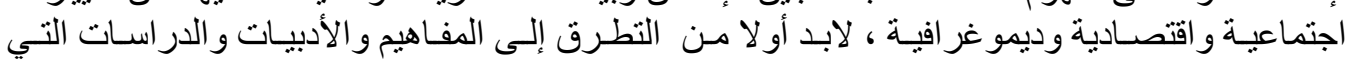

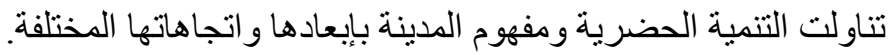

\section{1-2 مفهوم المدينة}

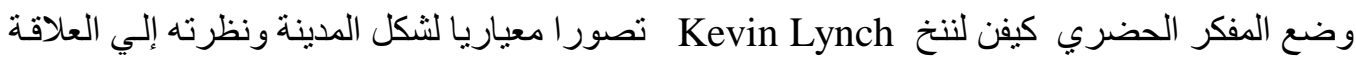

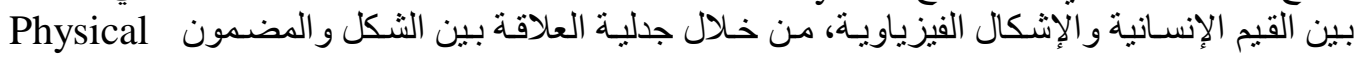
Forms Human Values

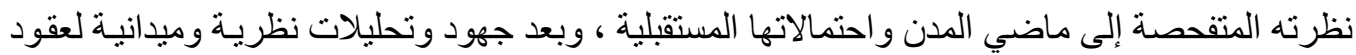

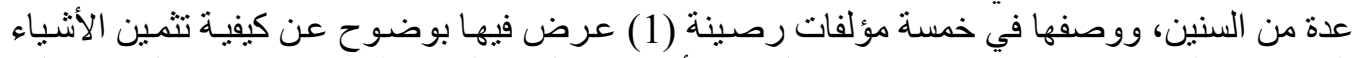

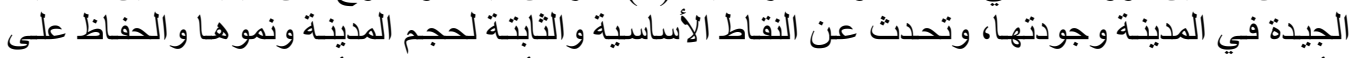

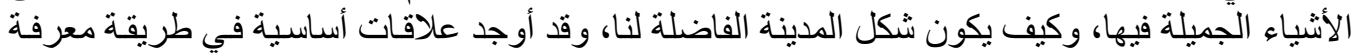

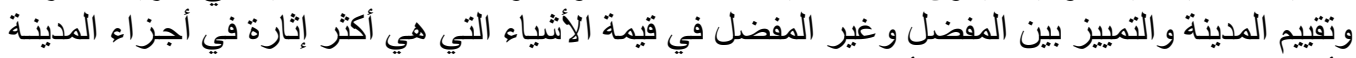

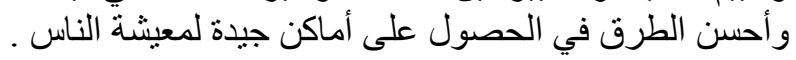

\section{2-2 النمو الحضري والتحضر}

عندما تكون معدلات الزيادة في سكان المدينة مساوية أو أقل من معدلات الزيات الزيادة في الإقليم الذي تشكيكل

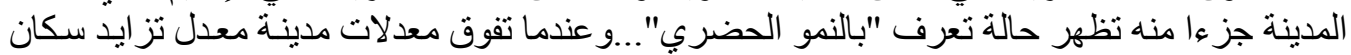

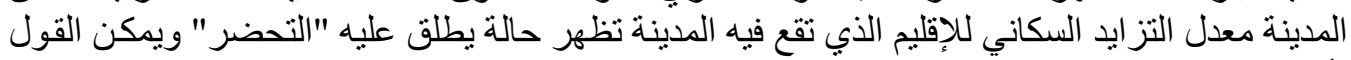

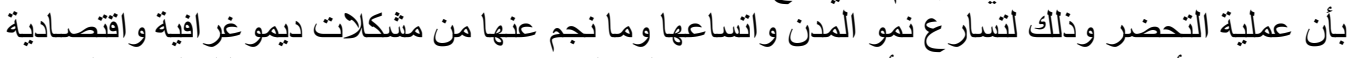

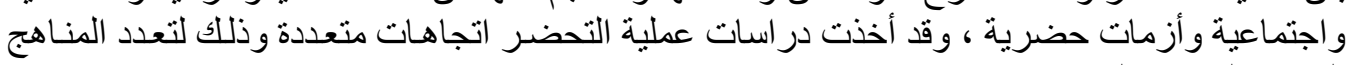

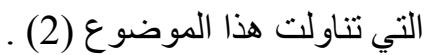

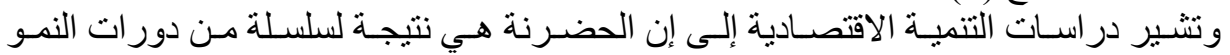

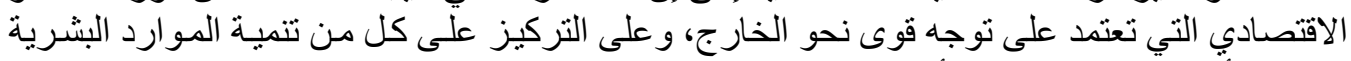

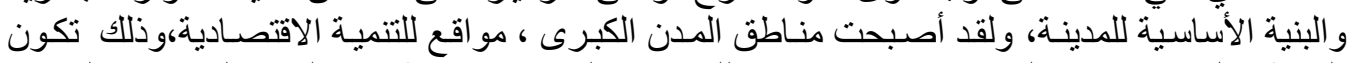

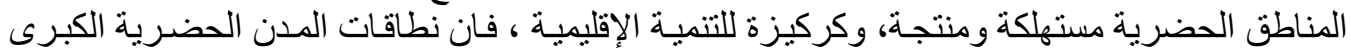

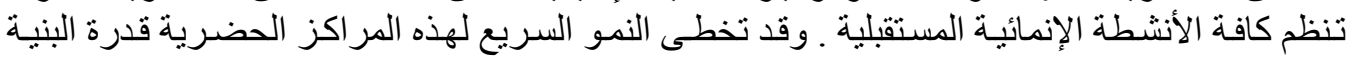




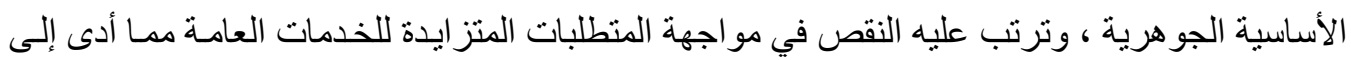

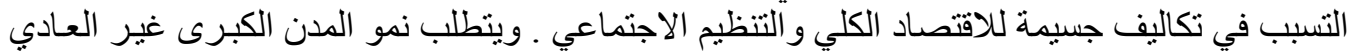

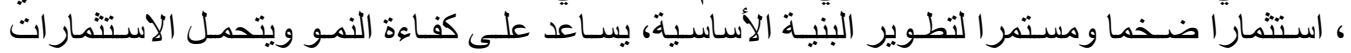

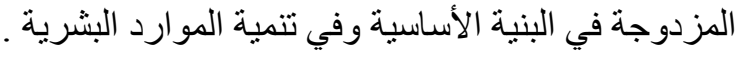

\section{3-2 التخطيط والبيئة المتوازنة فئة}

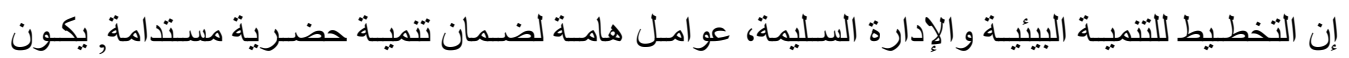

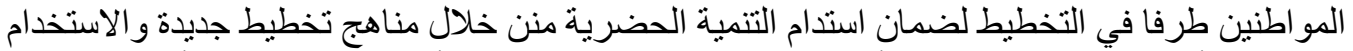

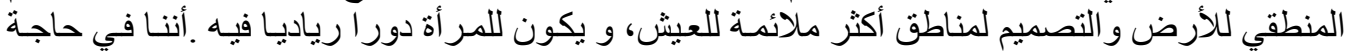

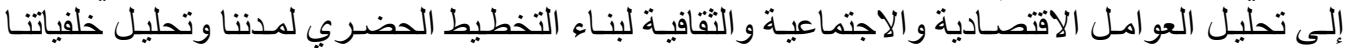

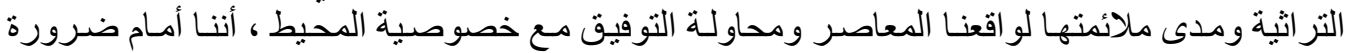

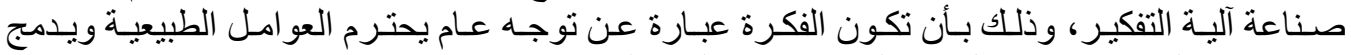

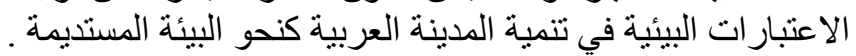

\section{4-2}

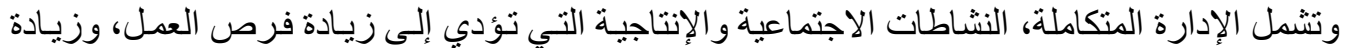

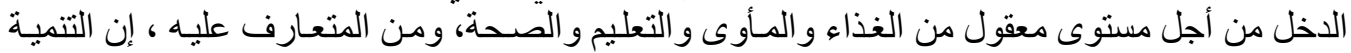

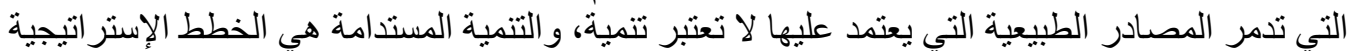

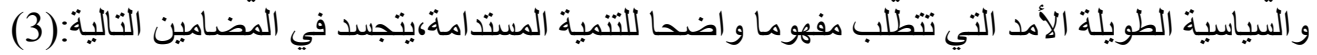

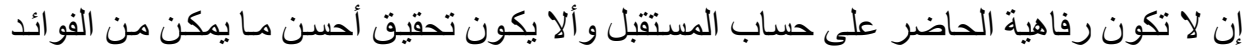

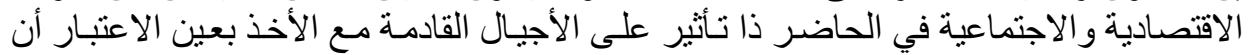
الموجودات البيئية الطبيعية ثابتة.

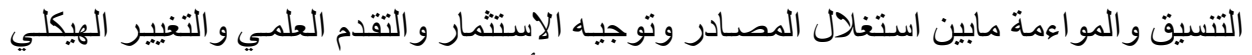

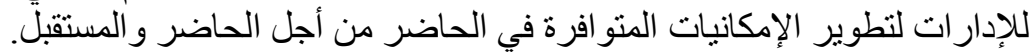

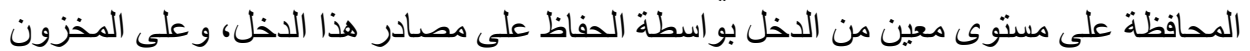

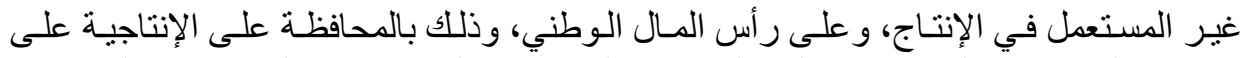

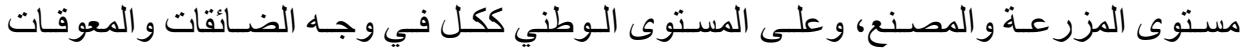
الاقتصادية. التنمية المستدامة للمناطق الزر اعة و الغابات والثروات السمكية ، هي إدارة المصسادر الطبيعيـة ،

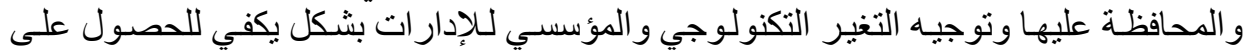

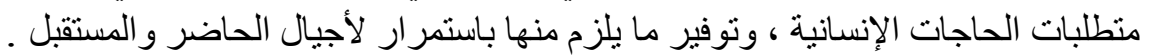

\section{3- 2 - دور المدن في التنمية}

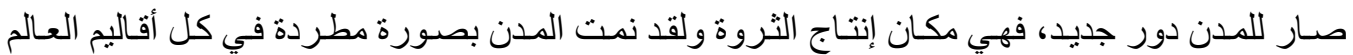

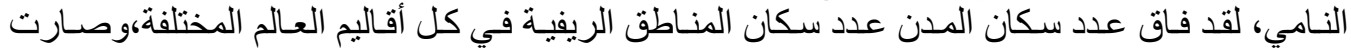

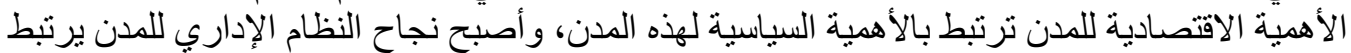

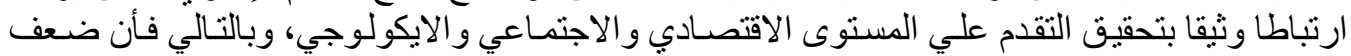
وفثل النظام الإداري يعني تدني مستوى النمو الاقتصادي وتفي الإنشي الفقر وتفاقم مشاكل البيئة. 


\section{1-3 تحولات المدينة العربية: الواقع والأفاق}

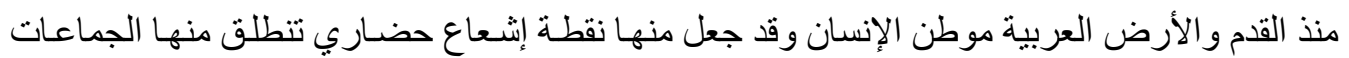

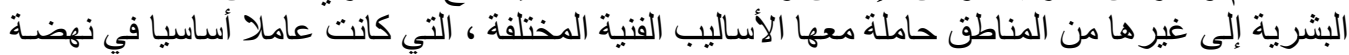

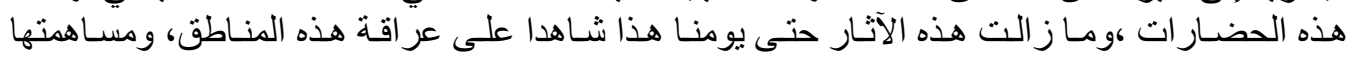

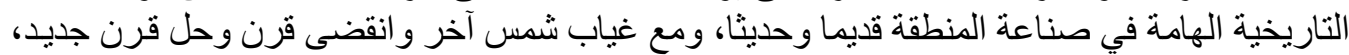

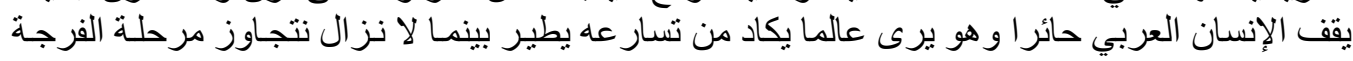

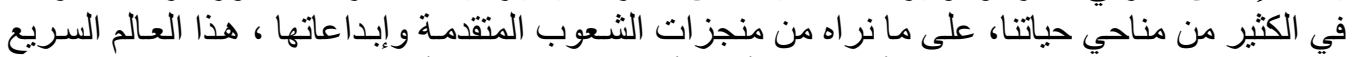

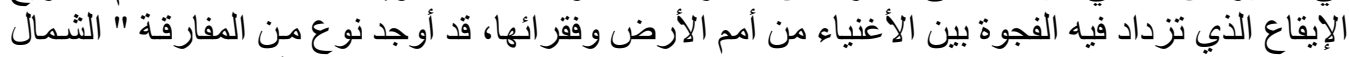

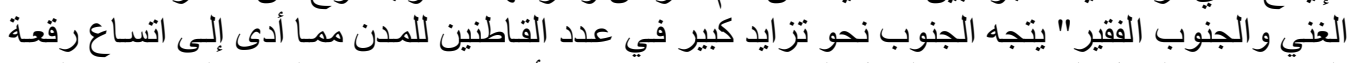

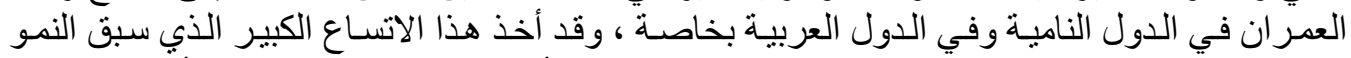

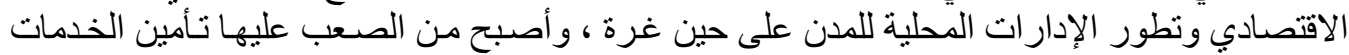

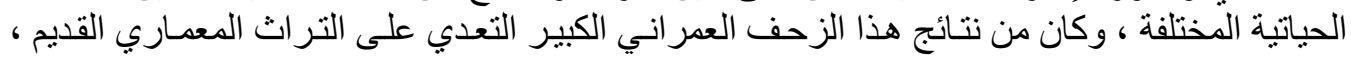

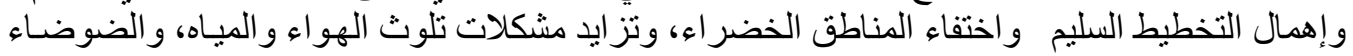

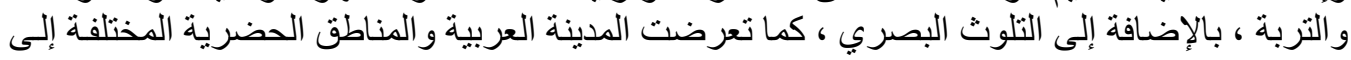

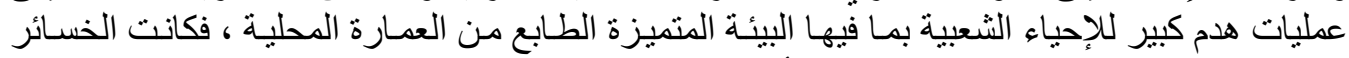

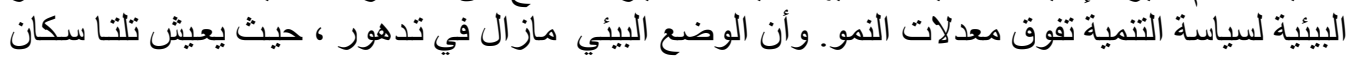

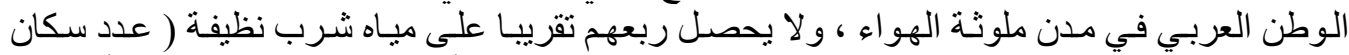

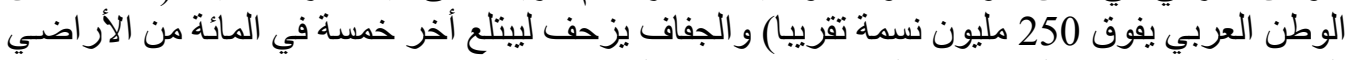

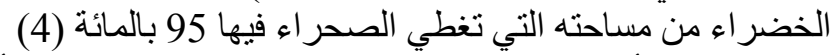

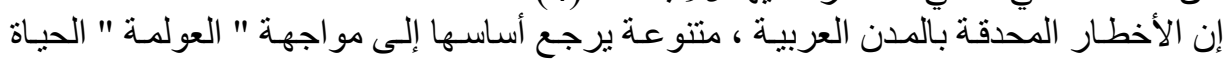

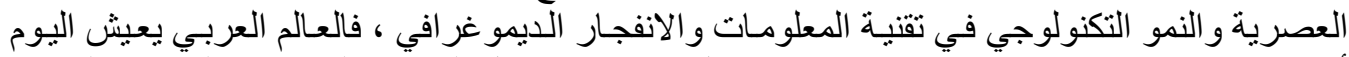

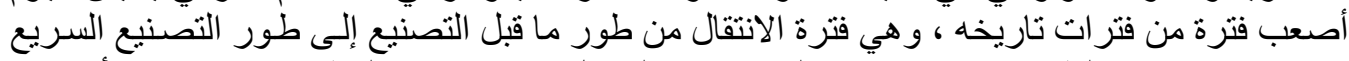

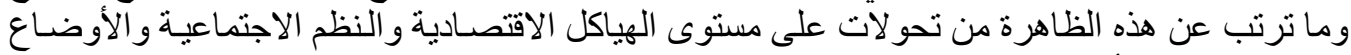

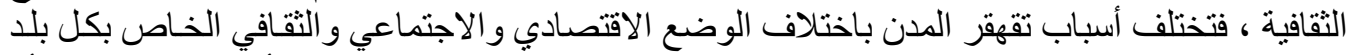

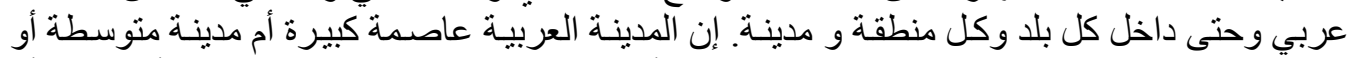

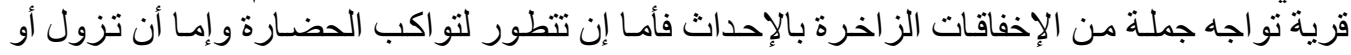

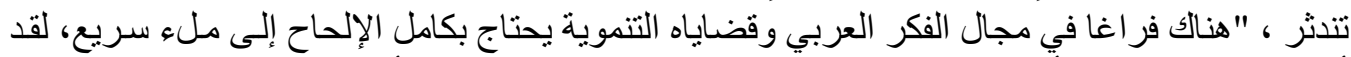

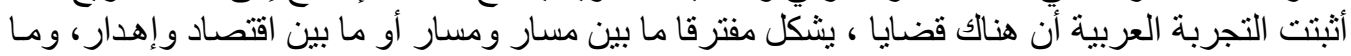

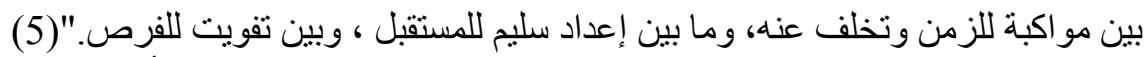

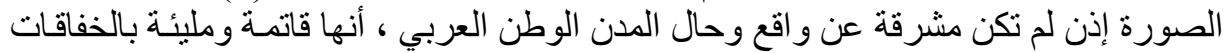

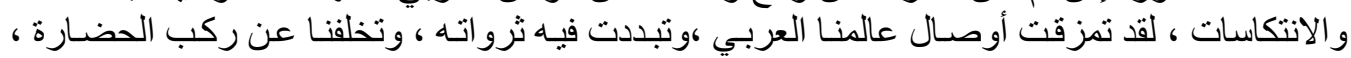

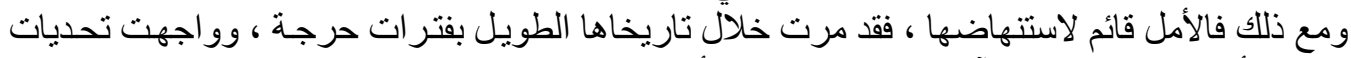

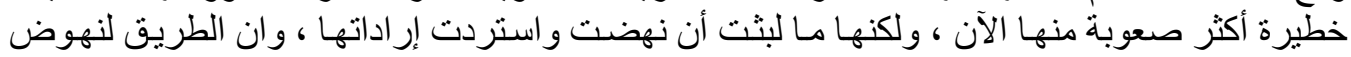

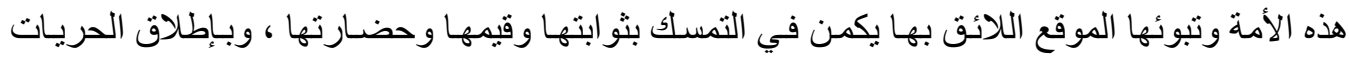

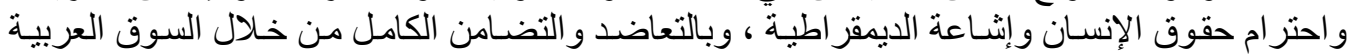

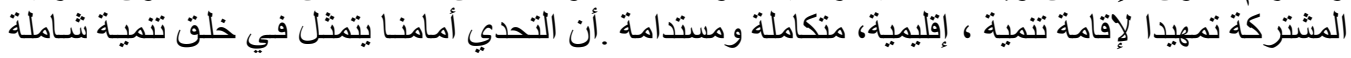

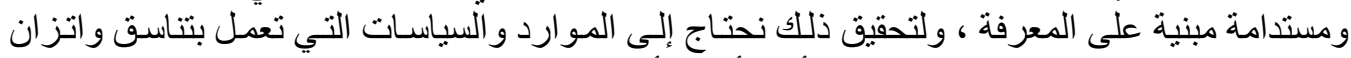

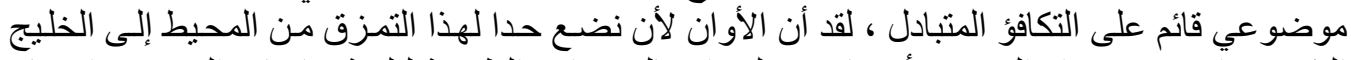

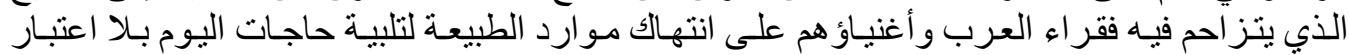




\section{2-3 مجريات المدن العمرانية}

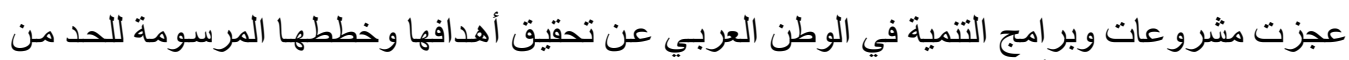

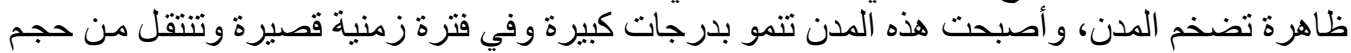

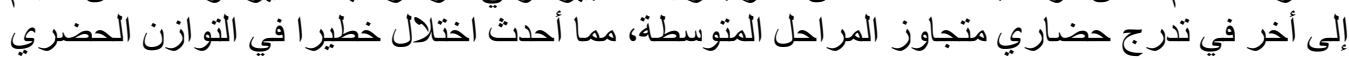

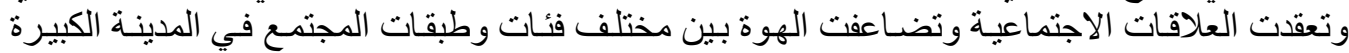

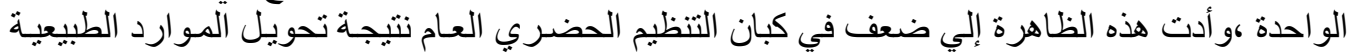

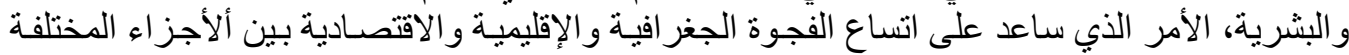

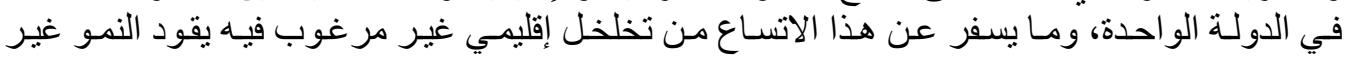

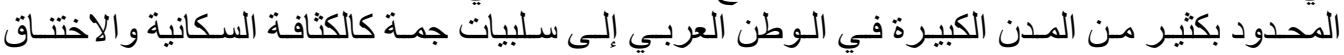

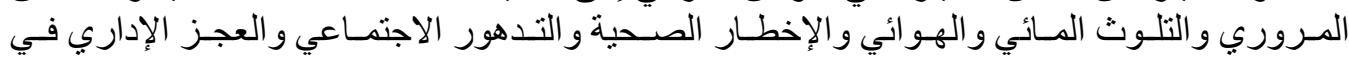

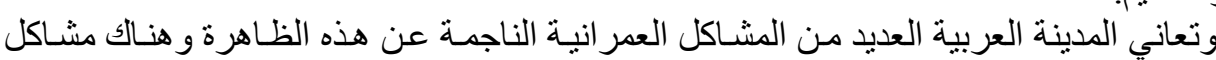

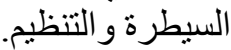

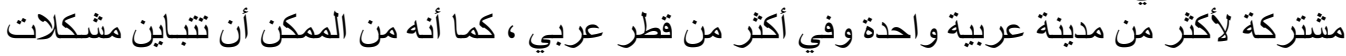

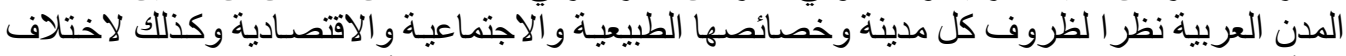

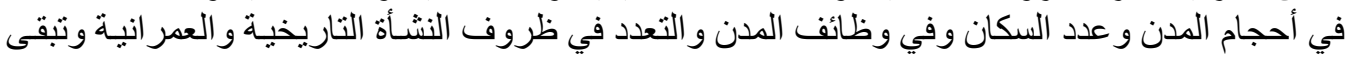

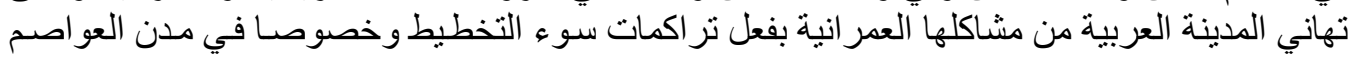

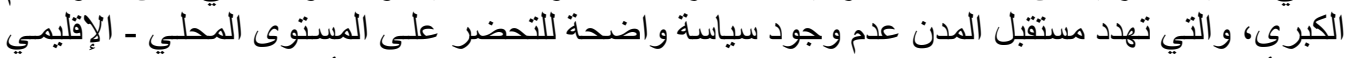

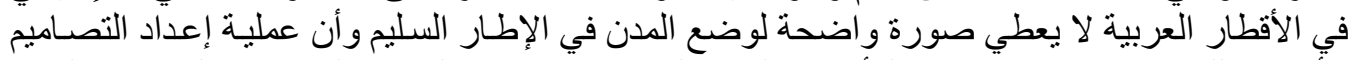

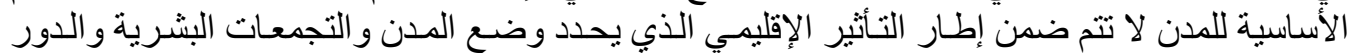

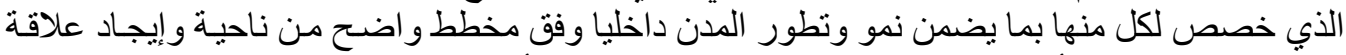

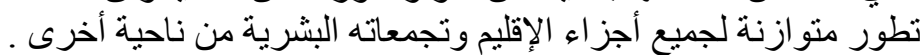

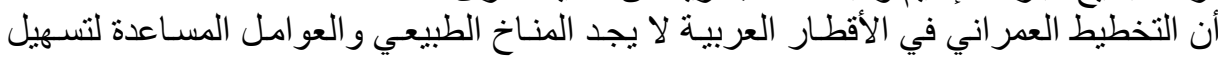

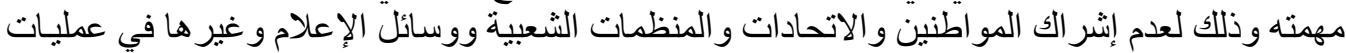

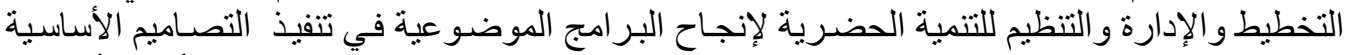

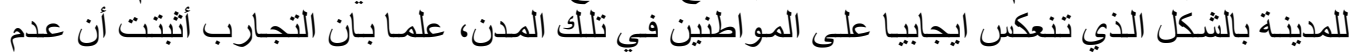

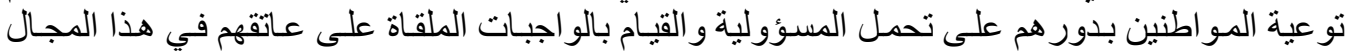

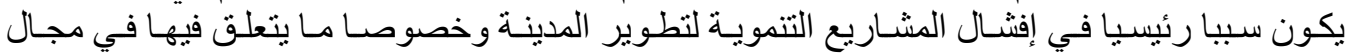

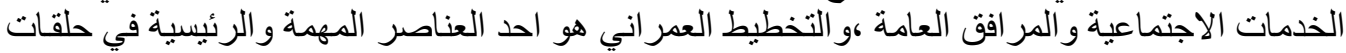

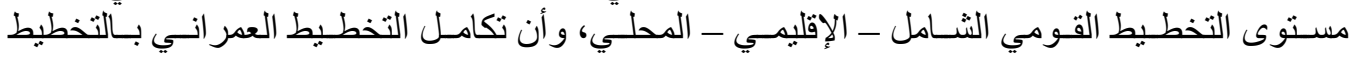

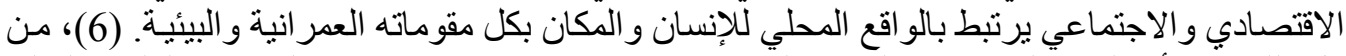

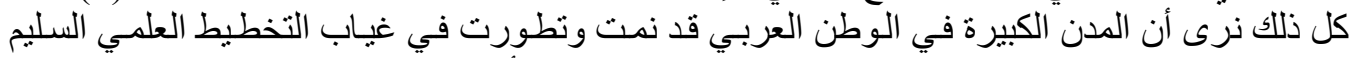

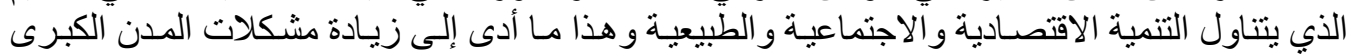

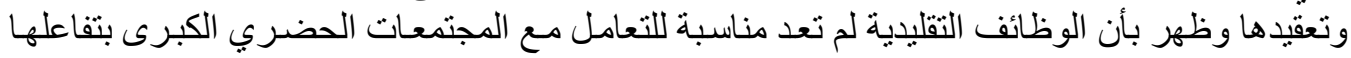

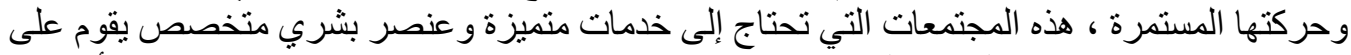

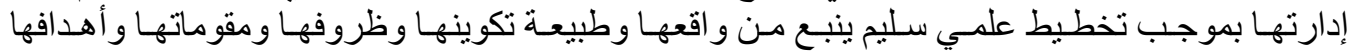

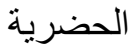

\section{المشهر الحضري للمدينة المعاصرة}

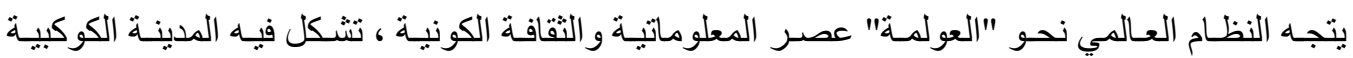

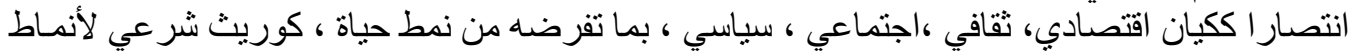

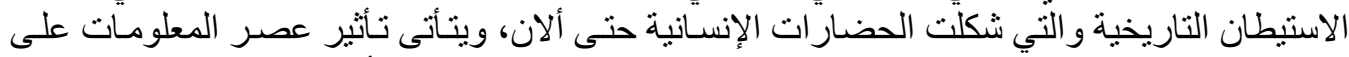

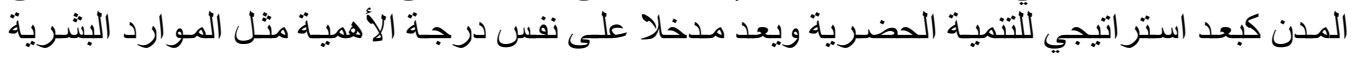




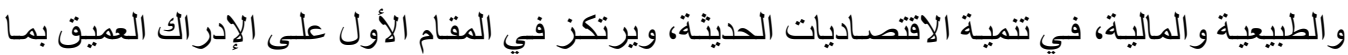

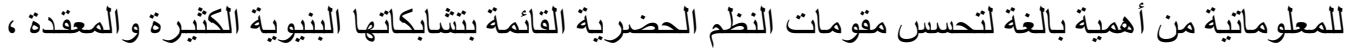

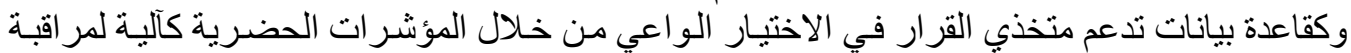

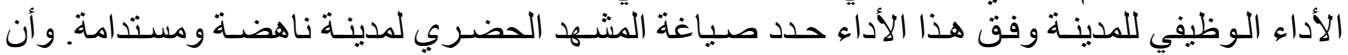

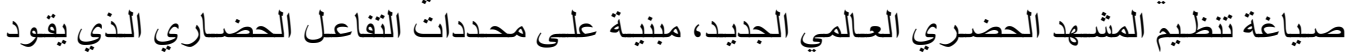

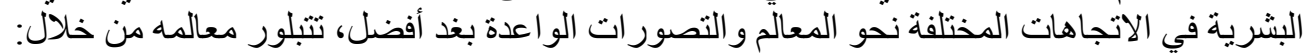

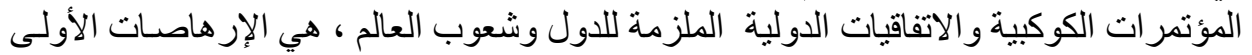

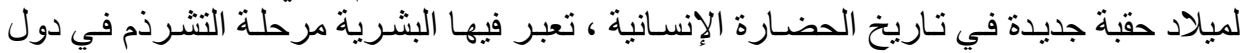

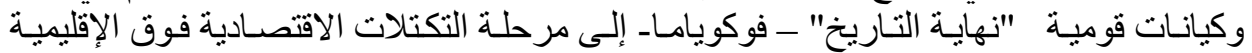

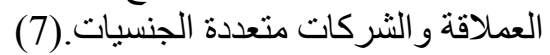

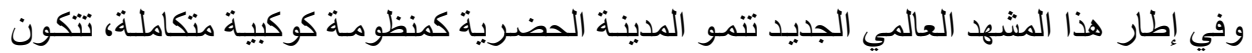

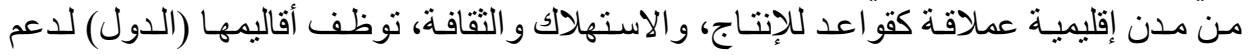

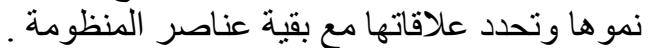

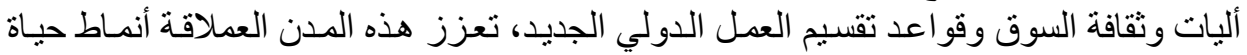

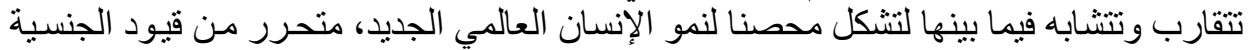

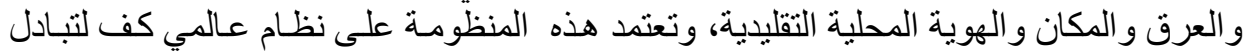

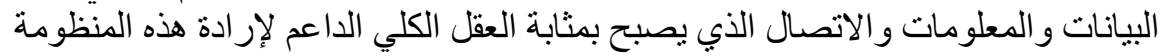

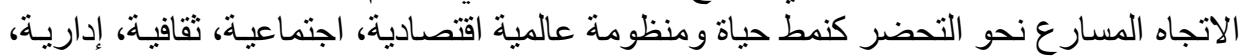

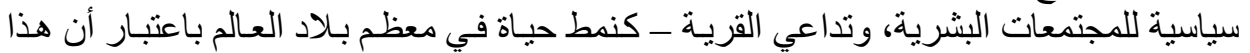

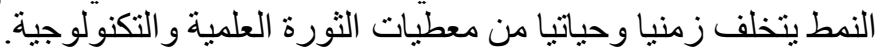

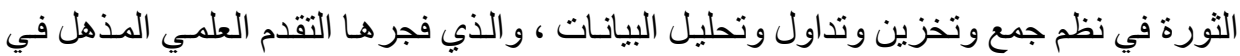

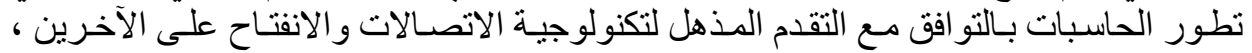

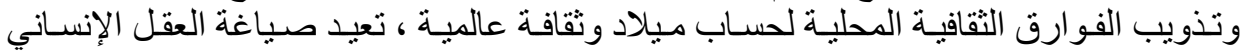

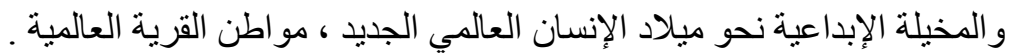

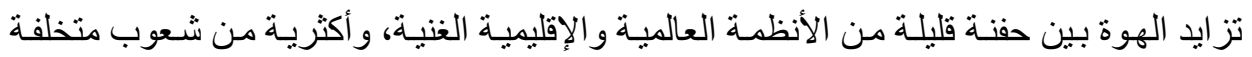
وفقيرة متدهورة منهوبة ومثقلة بالديون، غير قادرة حتى ألان على التنمية الحقيقية.

\section{4-3 أعادة تثكيل المدينة العربية}

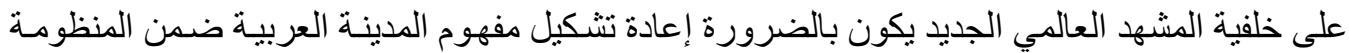

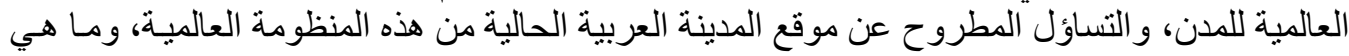

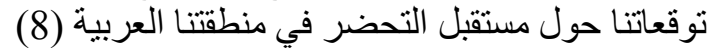

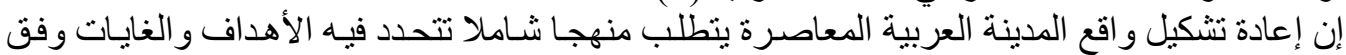

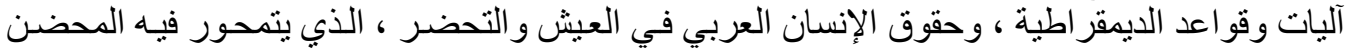

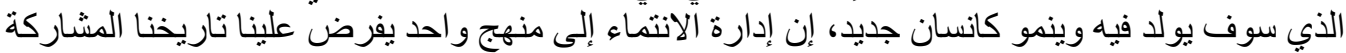

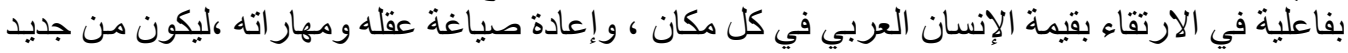

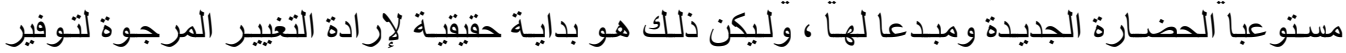

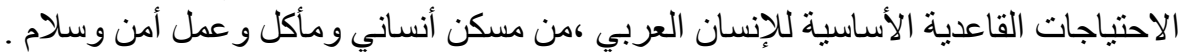

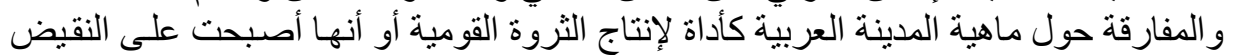

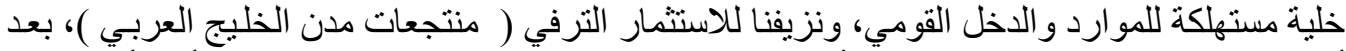

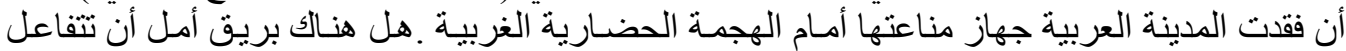

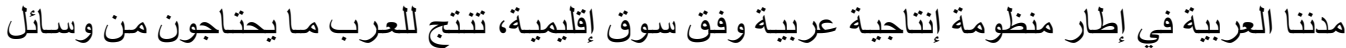
الحضار ات الر آقية، وتقام لأسو اق العالم منتجات ذات جونة دودة عالية. 
إن ملامح المجتمعات التي أفرزتها مدننا العربية المعاصرة، من خصائص المو اطن ابن المدينـة

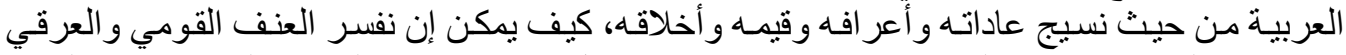

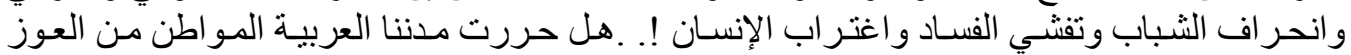

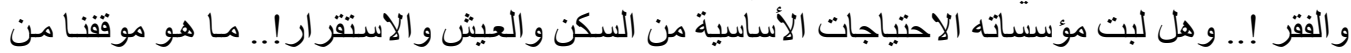

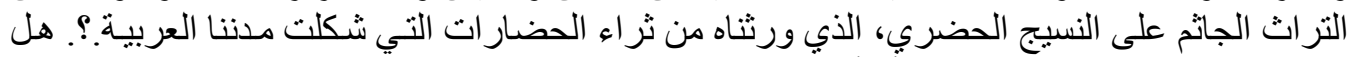

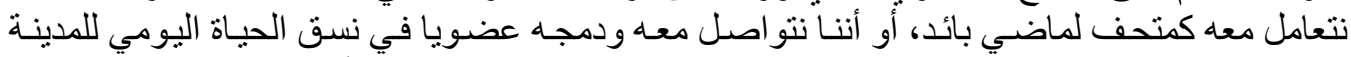

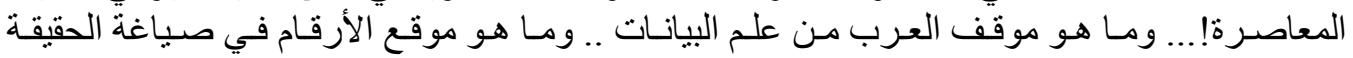

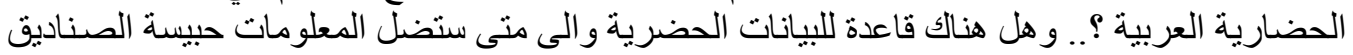

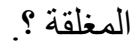

\section{4- إستراتيجية التنمية الشاملة بعيدة المدى}

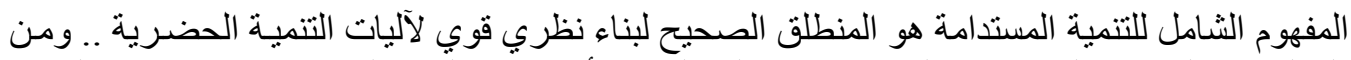

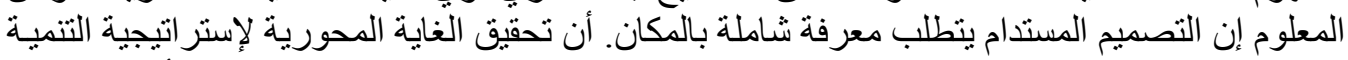

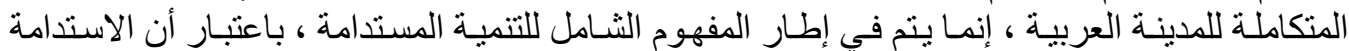

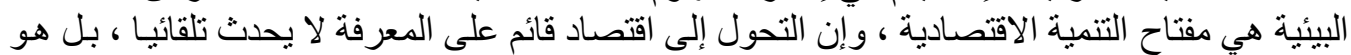

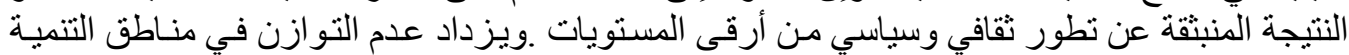

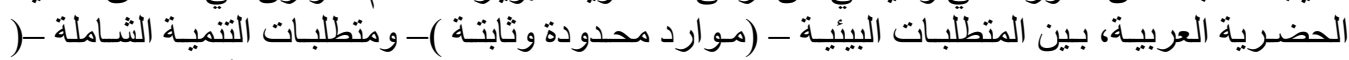

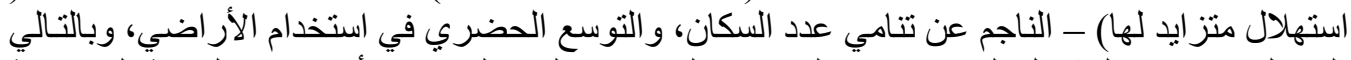

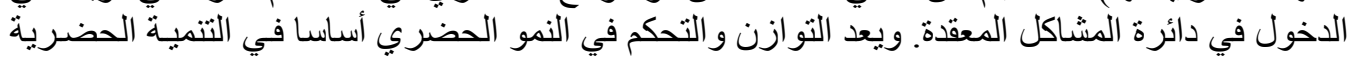

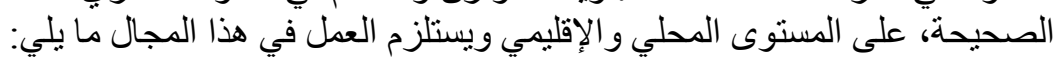

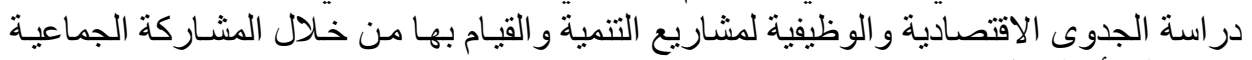
ودور المر أة الفاعل فيها.

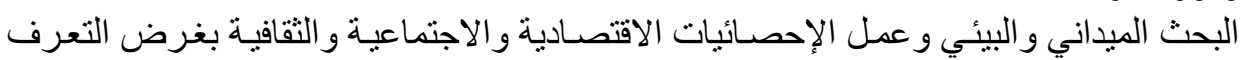
على حالات الوضع الرّا اهن، ثم التعرف على الإحلى التوقعات المستقبلية واستنباط معايير التنمية.

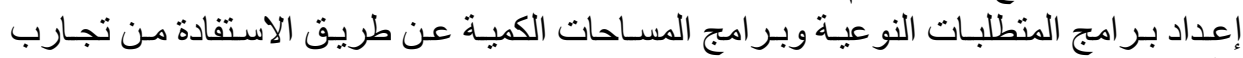
الآخرين واعدادئراعت الاعنماد ما يتناسب مع البيئة المحلية.

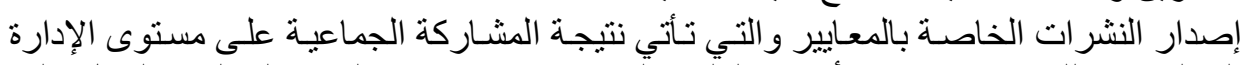

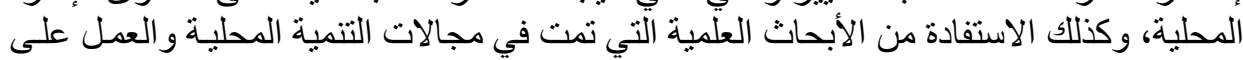
أخد التوصيات ومحاولة وكئة تطبيقها.

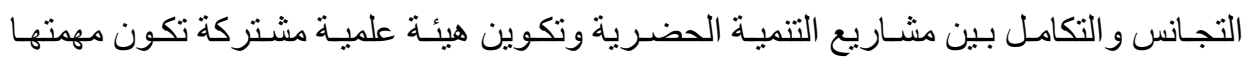

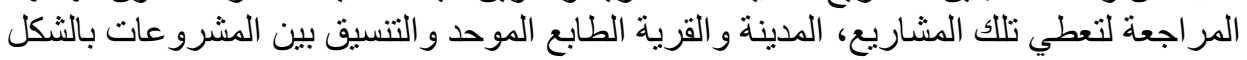

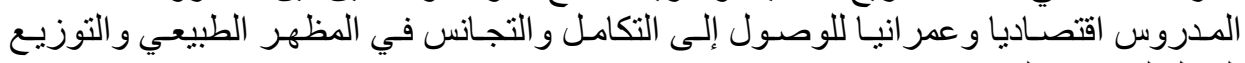
العادل لمستوى الخدمات.

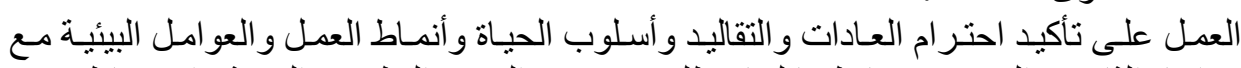

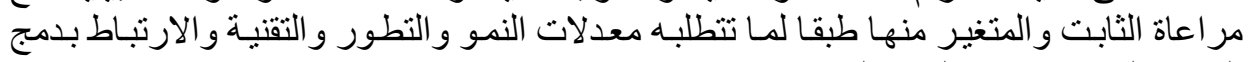

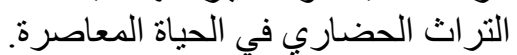

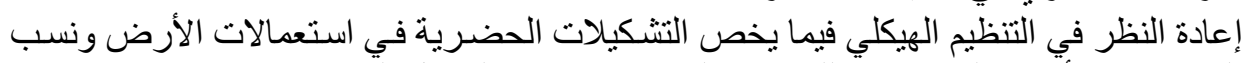

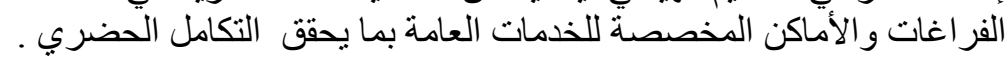

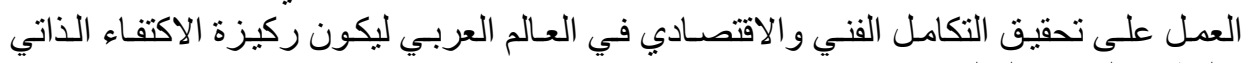

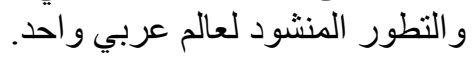


5- نماذج من خطط التطوير والتمية الحضرية لبعض المدان العربية:

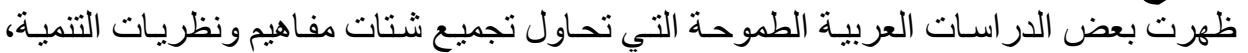

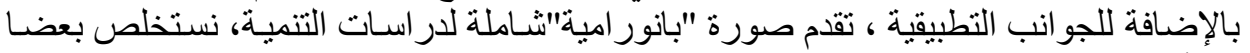
من أهم النماذج النطبيقية التالية:

\section{نموذج مدن الواجهة المائية في الخليج العربي التئي}

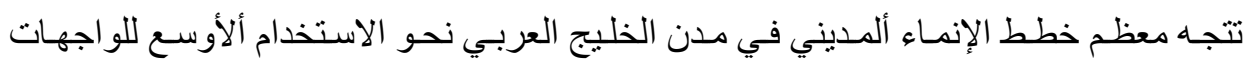

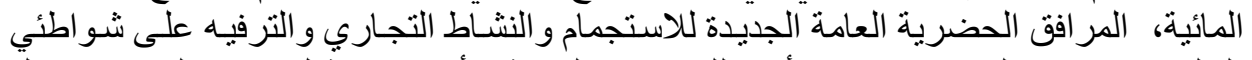

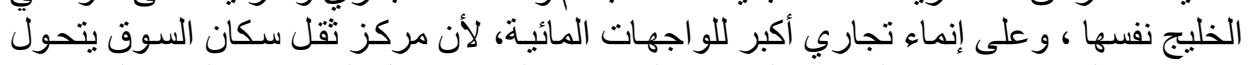

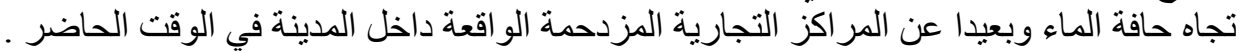

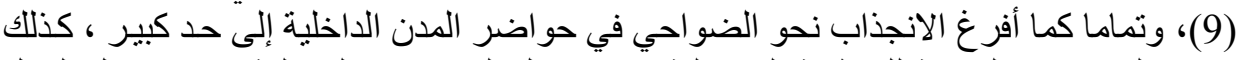

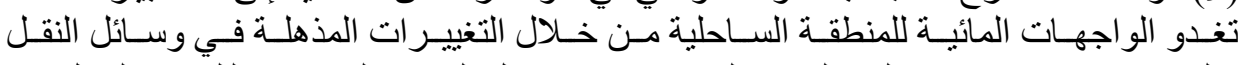

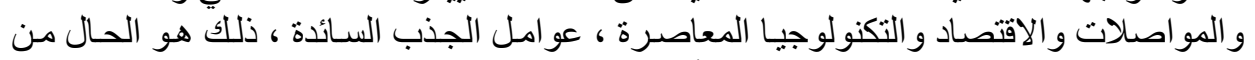

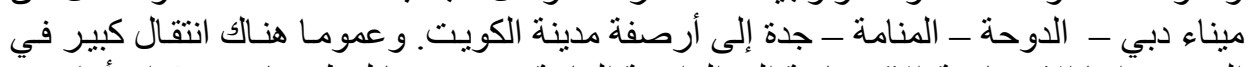

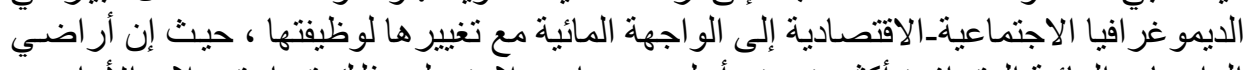

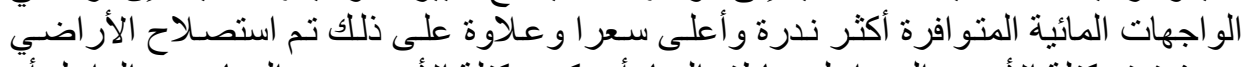

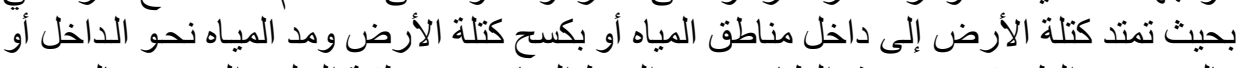

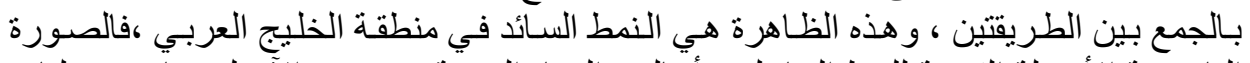

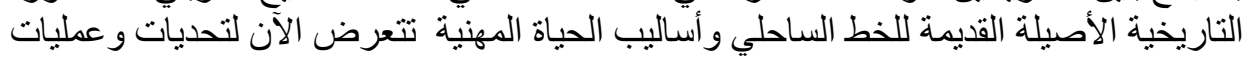

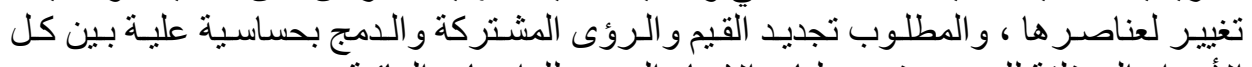

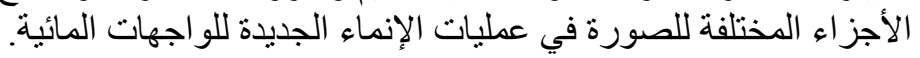

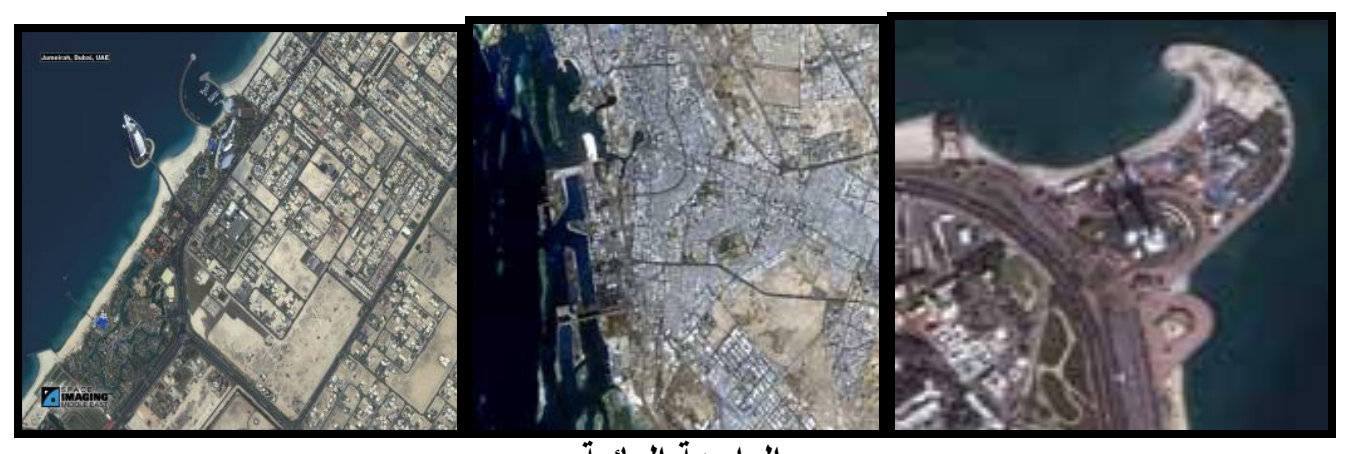

الواجهة المائية

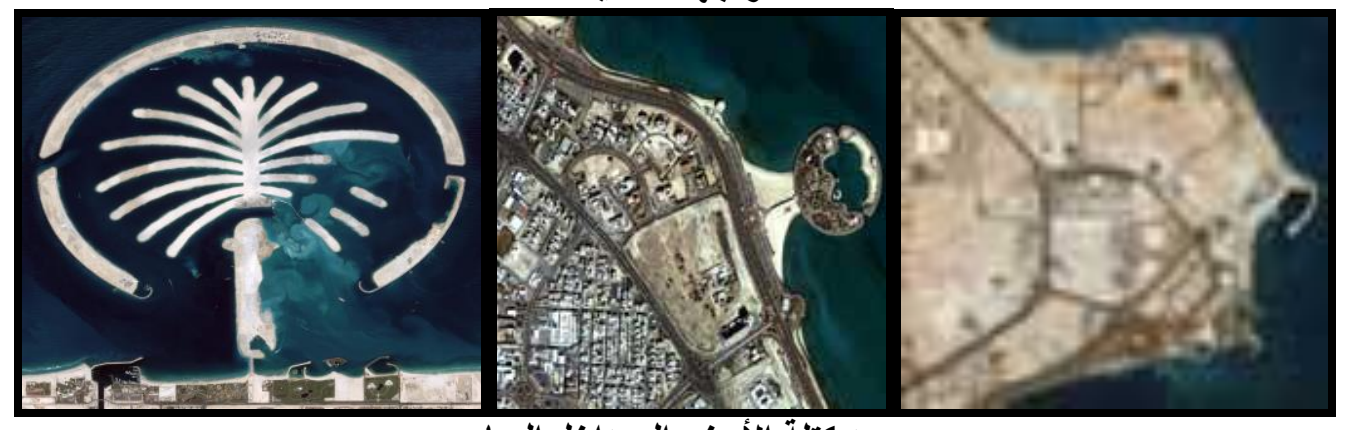

مد كتلة الأرض إلي داخل المياه 


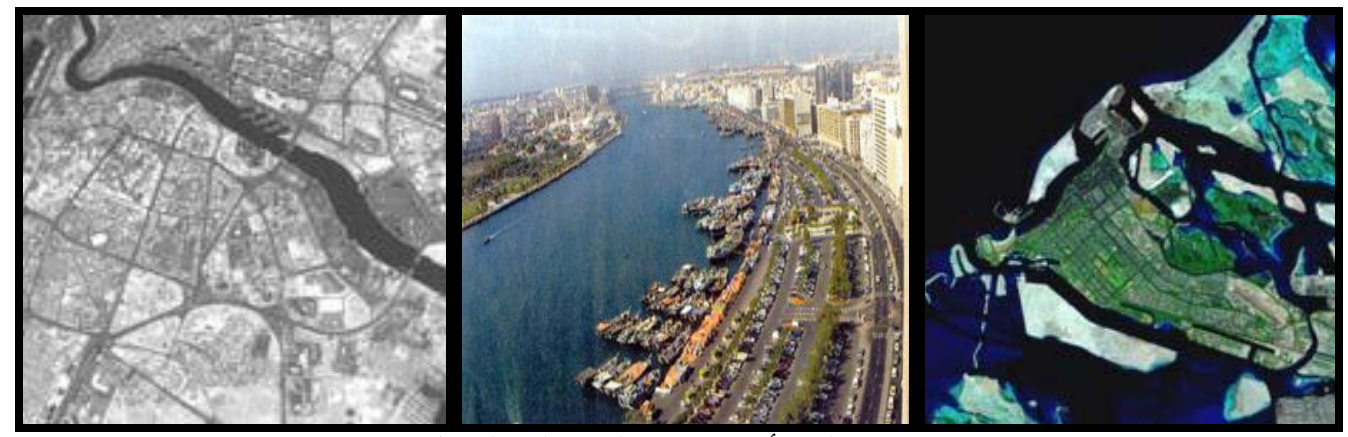

كسح كتلة الأرض ومد المياه إلى الداخل

شكل(1) مدن الخليج العربي

\section{تجربة التطوير الانفرادي}

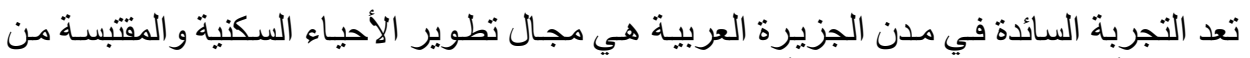

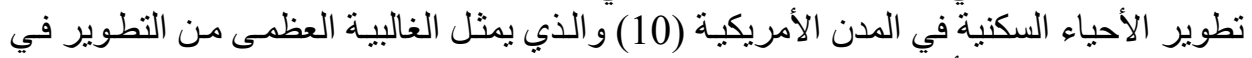

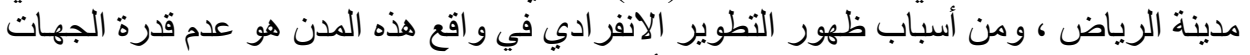

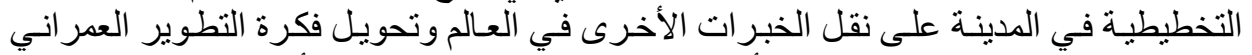

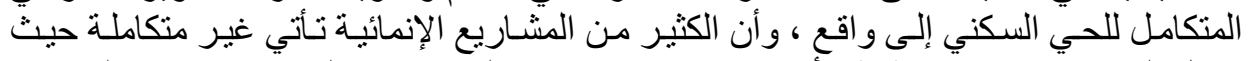

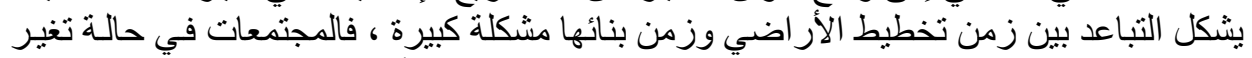

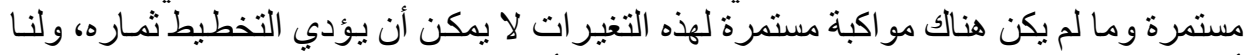

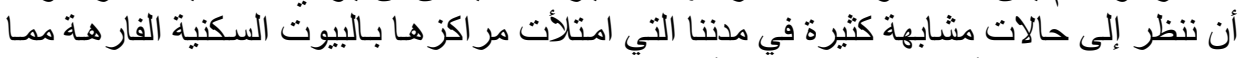

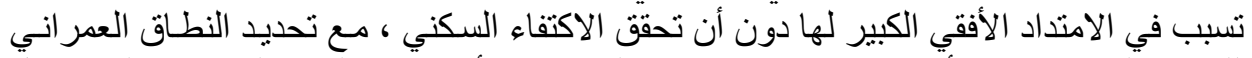

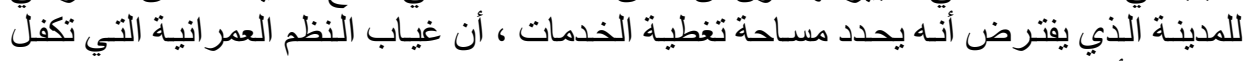

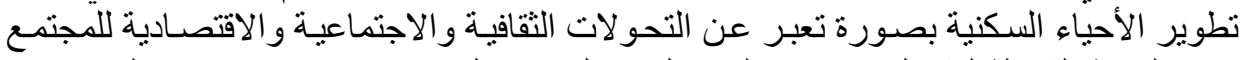

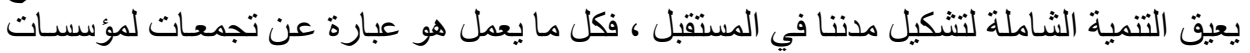

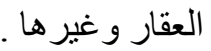
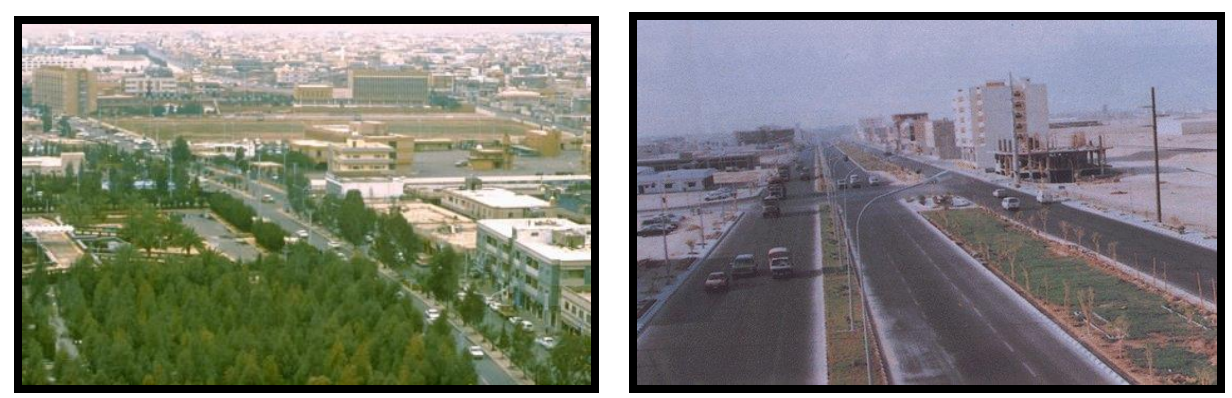

(شكل2) تجربة تطوير الأحياء السكنية في المدن السعودية

\section{المخطط العام لمدينة دمثق وعلاقة المدينة بمحيطها}

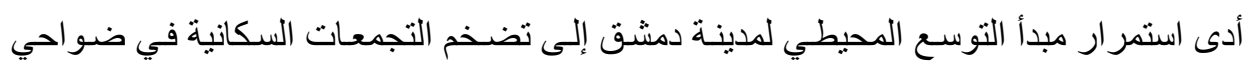

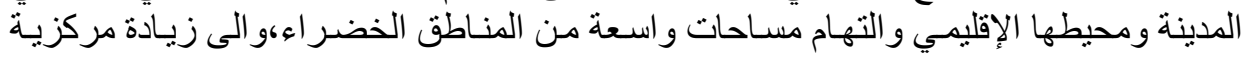




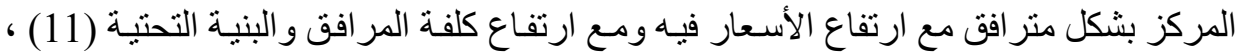

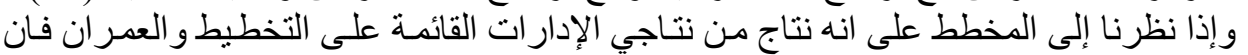

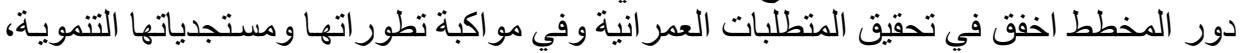

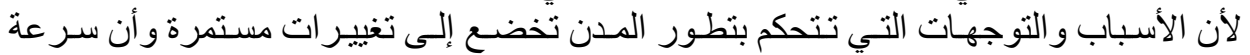

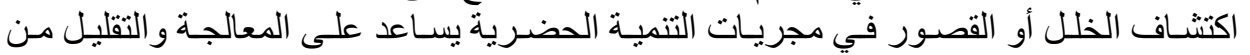

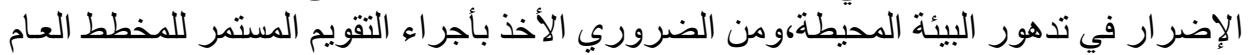

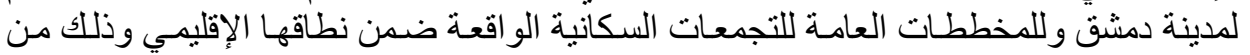

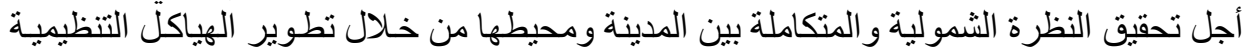

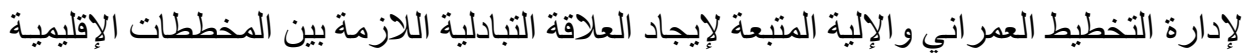
و والمدنية بمستو ياتها المختلفة.

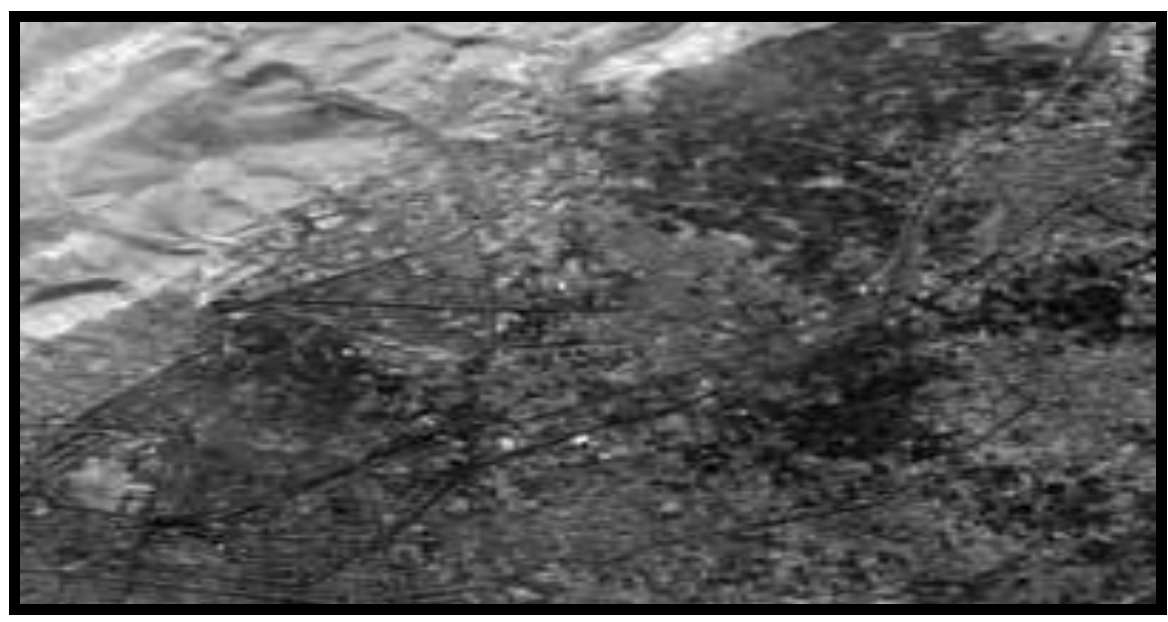

(شكل3) مدينة دمشق

\section{نموذج مدن المغرب العربي}

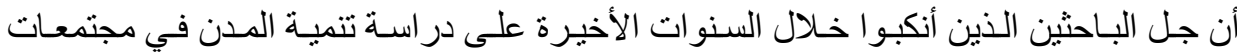

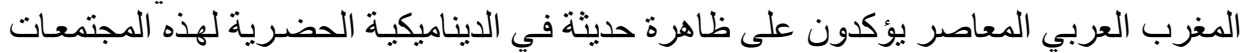

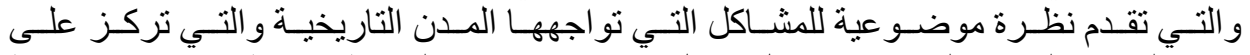

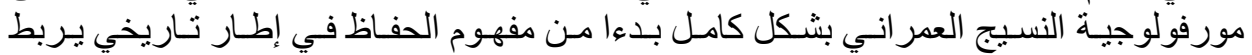

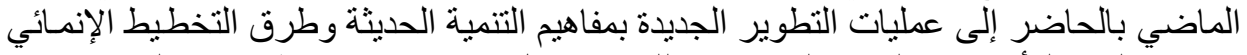

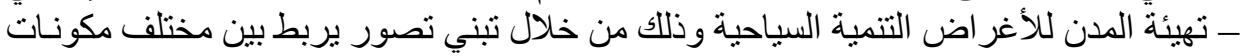

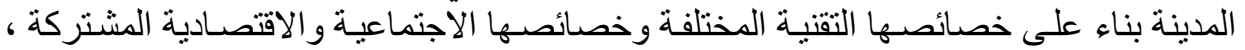
وأن الو اقع يتمحور حول الإنسان و المجتمع ـ نموذج مدينة الجزائر (12) 


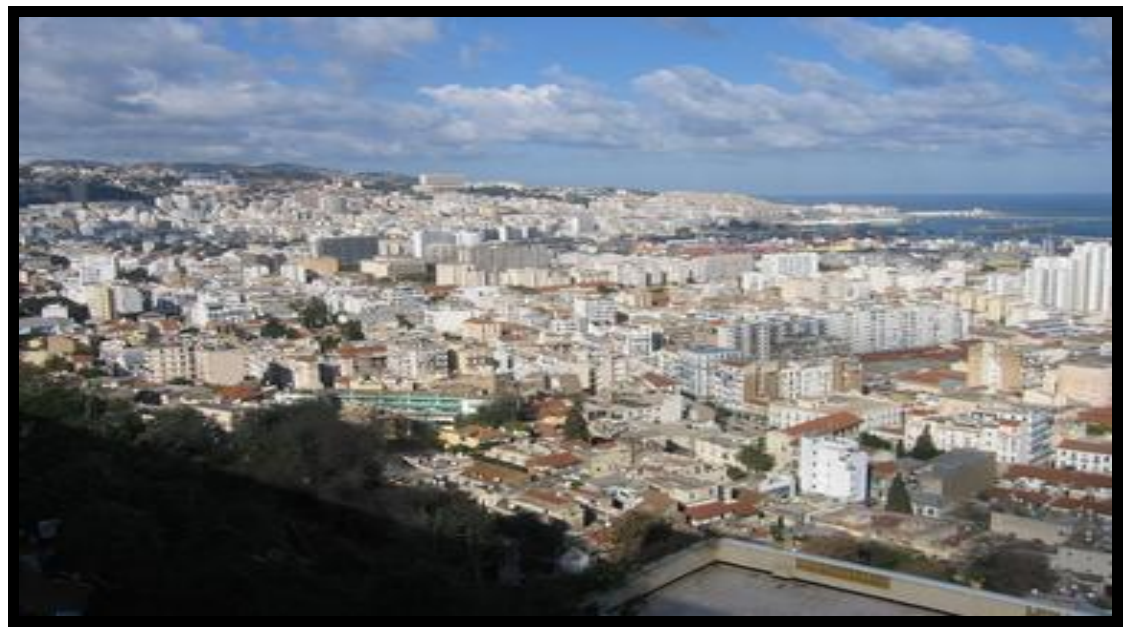

(شكل4) مدينة الجزائر

The New Urbanism النموذج العالمي: حركة العمران الجديد

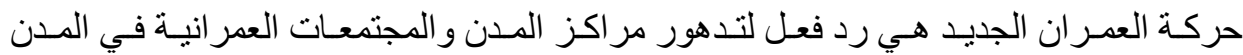

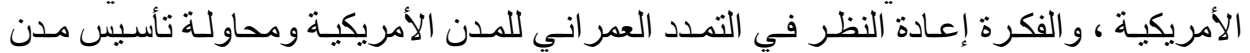

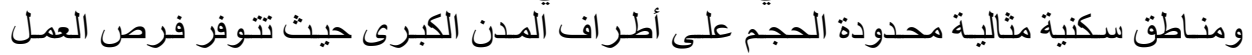

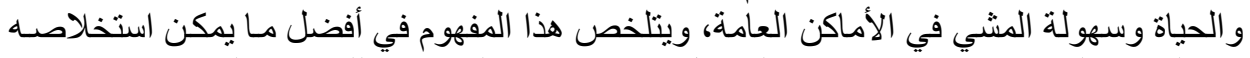

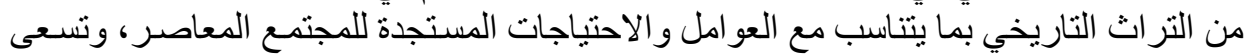

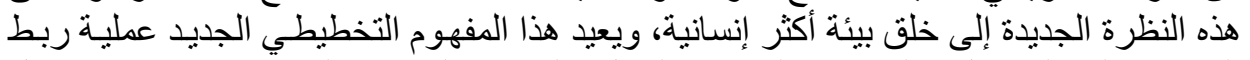

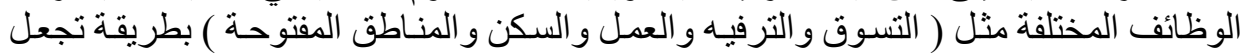

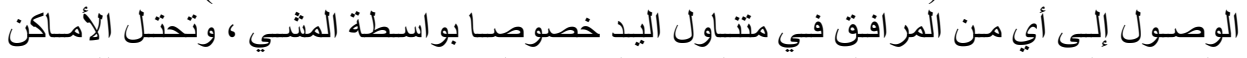

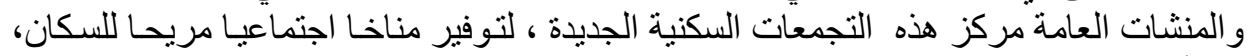

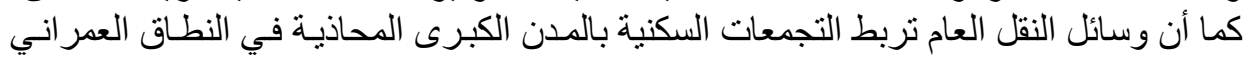

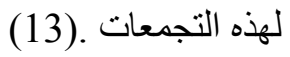

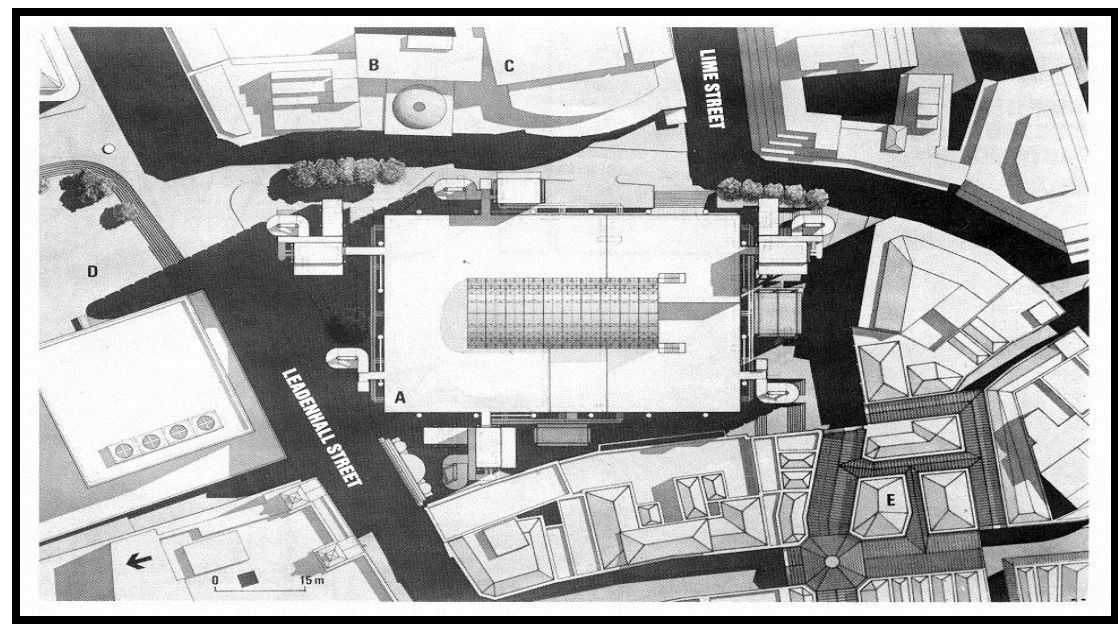

(شكل 5) مركة العمران الجديدة 


\section{• نموذج تطوير مدن المواني}

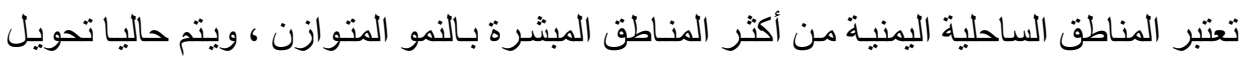

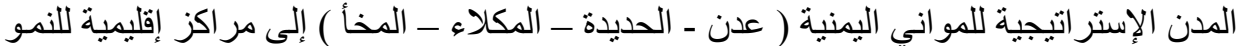

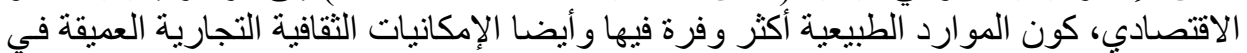

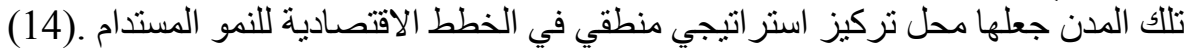

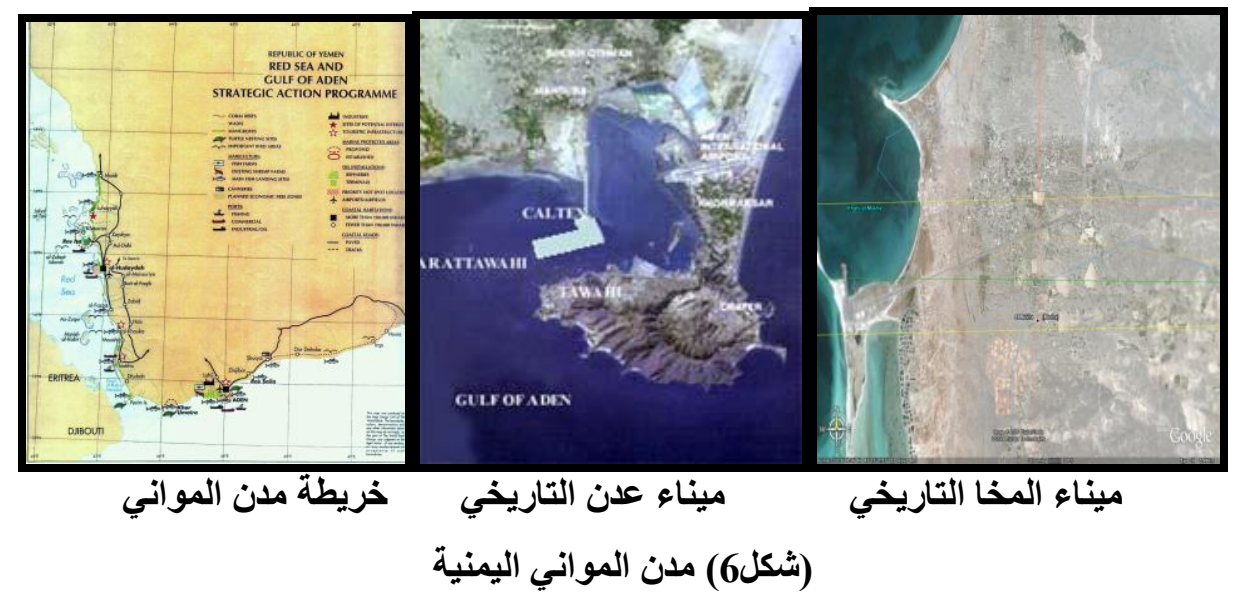

• الروية المستقبلية لمدينة عدن

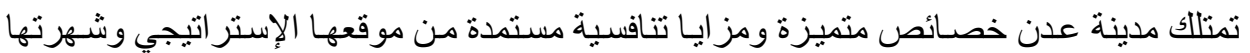

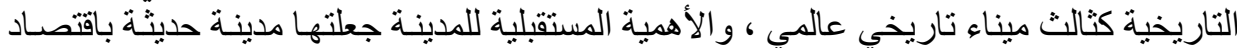
يرتكز على خدمات بحريـة، جويـة ،تجاريـة دولية ولية وخدمات سياحية مستخدمة قدر اتها التنافسية لتكون قطبا جاذبا للاستثمار المحلي و الدولي .

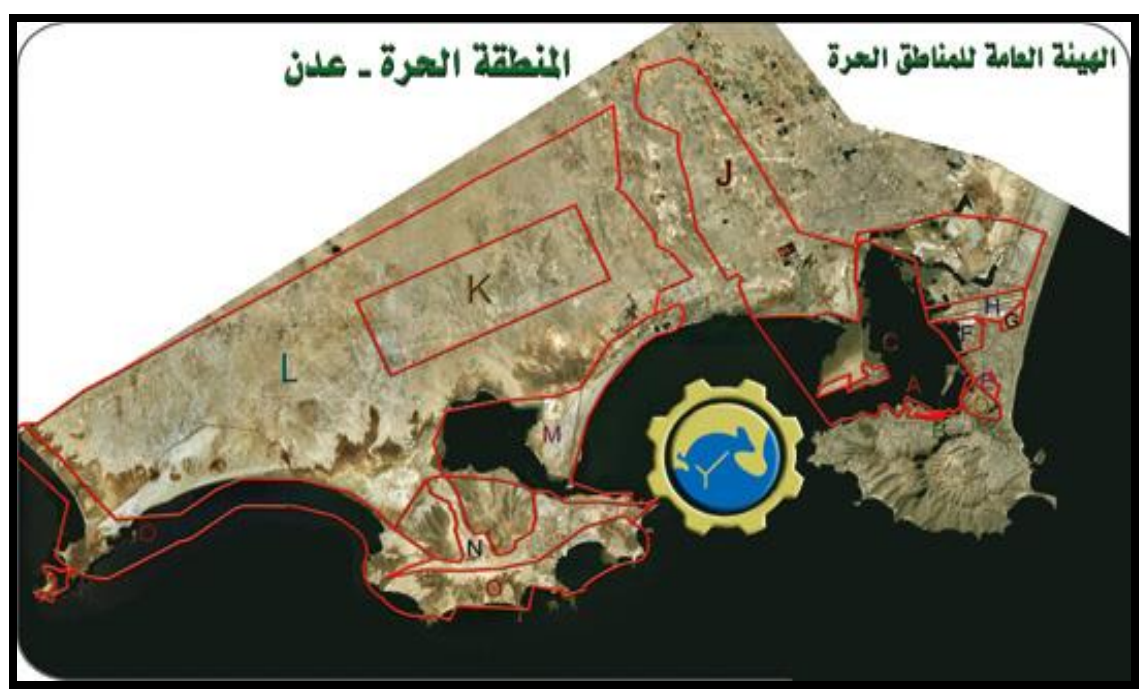

(شكل7) خطة التنمية المستقبلية لمدينة عدن 


\section{إستراتيجيات التنمية المستدامة وفقا لمعايير " تحالف المدن "}

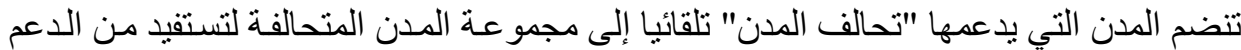

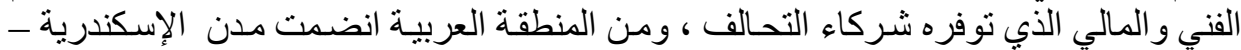

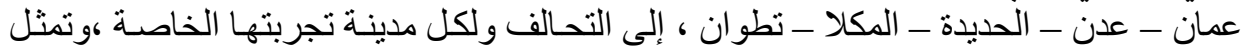

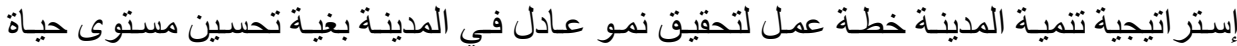

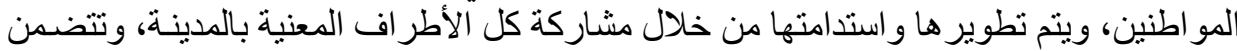

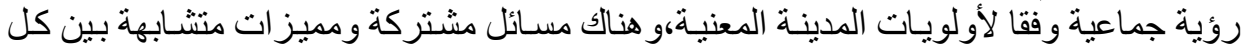

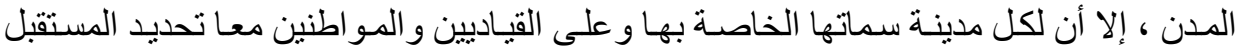

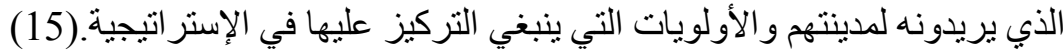

\section{6- 6 استنتاجات وتوصيات}

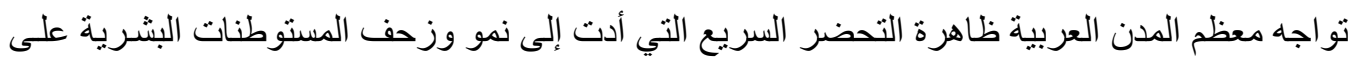

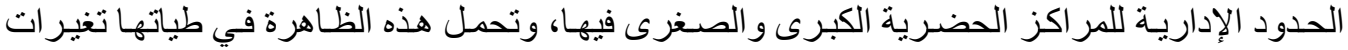

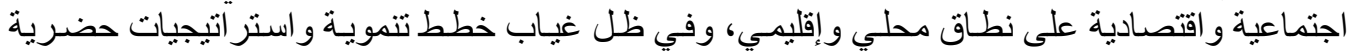

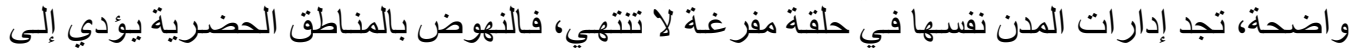

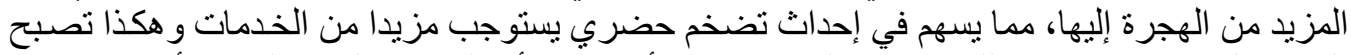

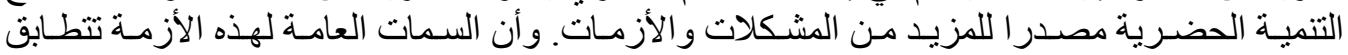

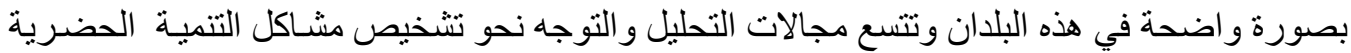

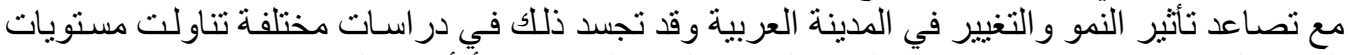

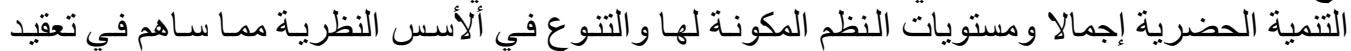

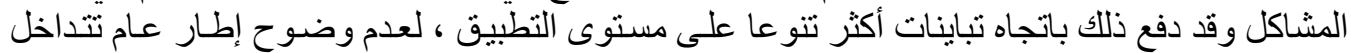

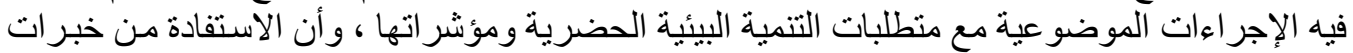

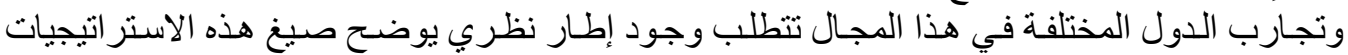

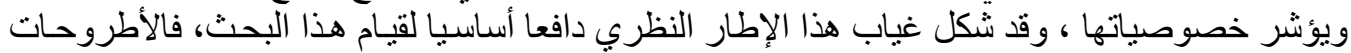

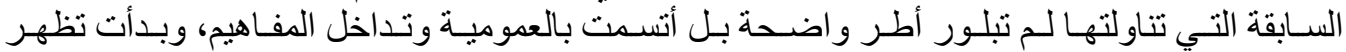

ممارسات لاستنساخ الحلول وتنكر ارها.

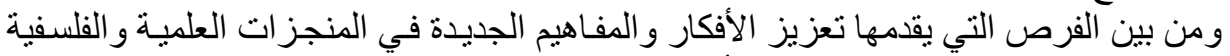

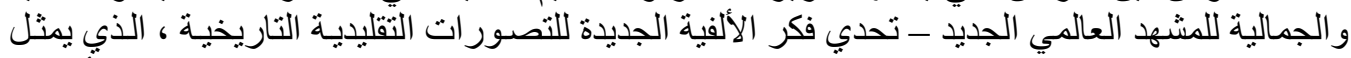

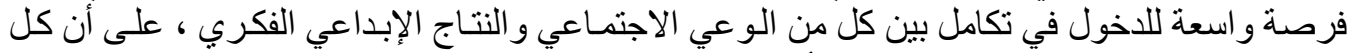

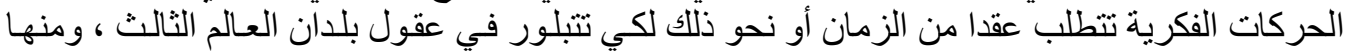

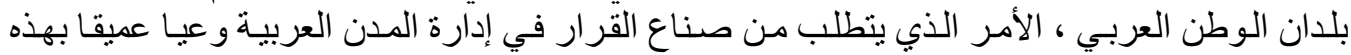

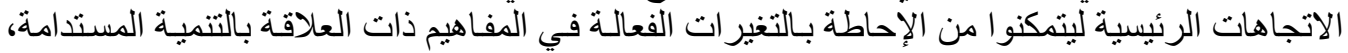

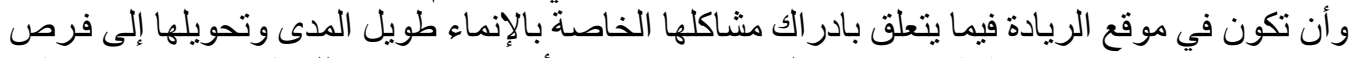

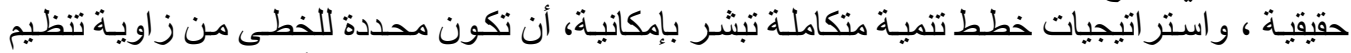

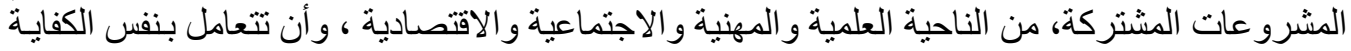

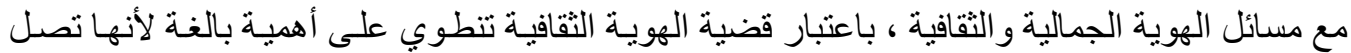

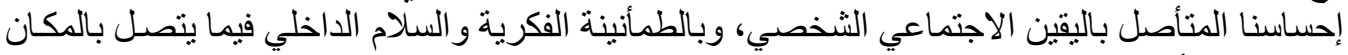

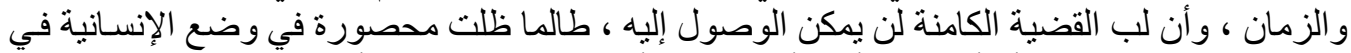

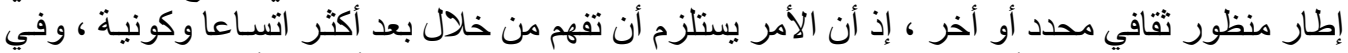

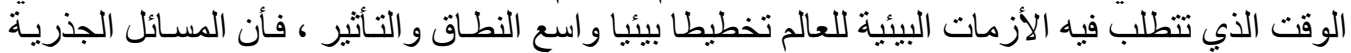

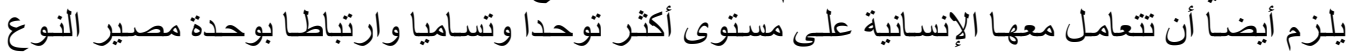




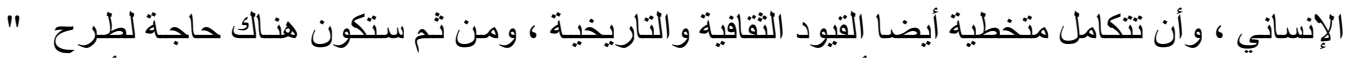

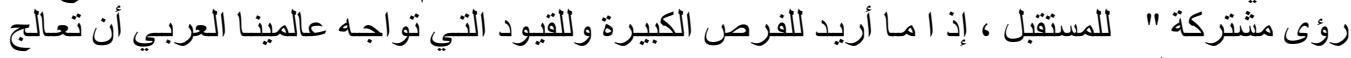

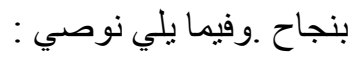

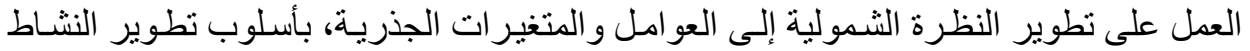

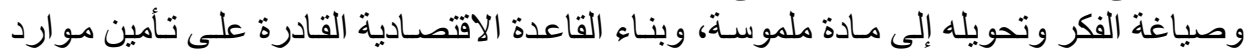
متجددة محلية ومتطورة و أنظمة بنائية حديثة.

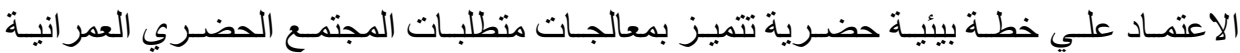

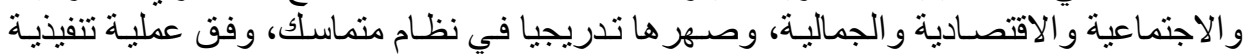

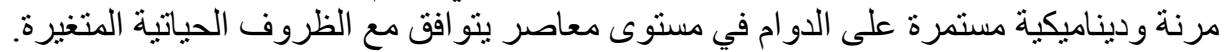

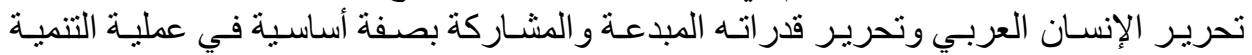
و التمتع بثمار التنمية . الانية تسريع التنمية الثاملة المنسمة بتحقيق أكبر قدر من الاعتمـاد القومي علي الذات والتئة والمحققة أكبر

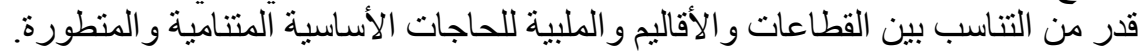

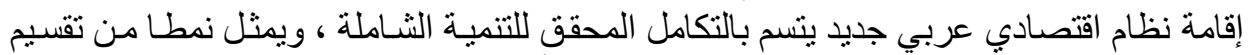

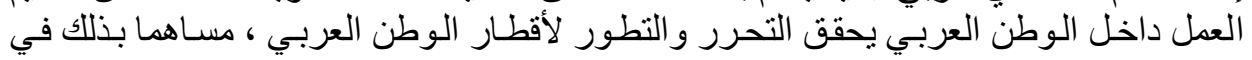

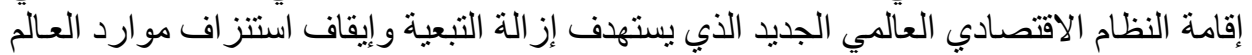
العربي و إقامة علاقات اقتصادية العالية متكافئة و عادلة الألة.

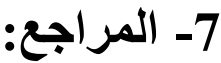

1. الكبسي،فلاح صباح- "التصميم الحضري- مبادئ وتكنولوجيا" مركز عبادي للار اسات و النشر

صنعاء 1998م الفيناح

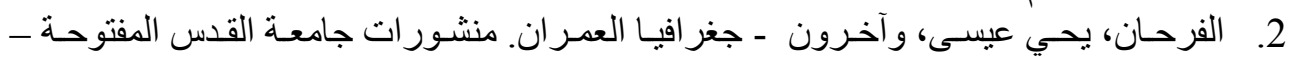

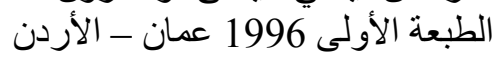

3. سياسات و استر اتيجيات وقضايا التنمية المستدامة، تقرير حالة سكان العالم 1996م ـصندوق

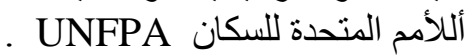

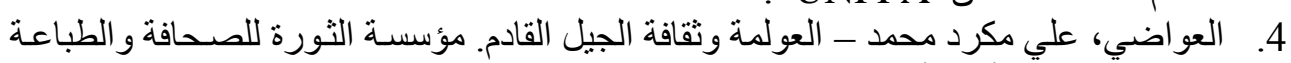

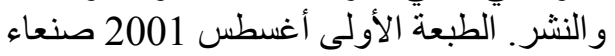

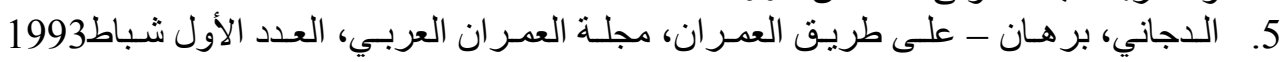
بيروت- لبنان

6. الحيدري، علي - التصميم الحضري، الهيكل و الدراسات الميدانيةـ مكتبة مدبولي 2002

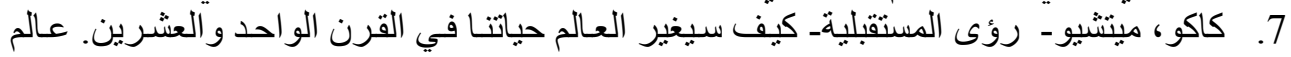

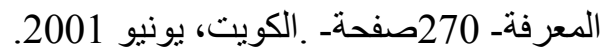

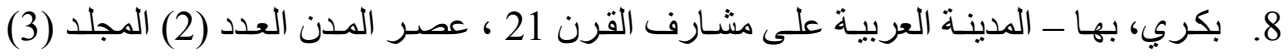
يونيو 1995.

9. أحمد، إبر اهيم - عمارة الو اجهة المائية في الخليج - عالم الفكر المجلد (27) العدد (2) أكتوبر / دبسيمبر 1998 الكويت.

10. السكيت، خالد ـ نطوير الإحياء السكنية في السعودية السنة (21) العدد (130) يونيو 2001 (21)

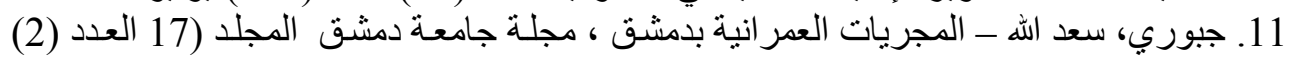
2001 12. مدن المغرب العربي - مجلة العو اصم و المدن الإسلامية العدد (30) يناير 2001. 13. السكيث: المرجع السابق السيق 
14. الإستر اتيجية التنموية لمدينة عدن - برنامج تطوير مدن المو اني اليمنية 2005 15. إستر اتيجية تنمية المدن ومعايير " تحالف المدن " ورشـة عمل إطنلاق إستر اتيجية تنمية مدينة

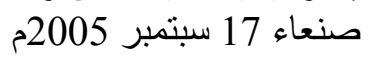

